\title{
Auto-ignition of Direct Injection Spray of Light Naphtha, Primary Reference fuels, Gasoline and Gasoline Surrogate
}

\author{
Libing Wang ${ }^{1}$, Zengyang Wu${ }^{1}$, Ahfaz Ahmed ${ }^{2}$, Jihad A. Badra ${ }^{3}$, S. Mani Sarathy ${ }^{2}$, \\ William L. Roberts ${ }^{2}$, Tiegang Fang, ${ }^{1, *}$ \\ ${ }^{1}$ Department of Mechanical and Aerospace Engineering \\ North Carolina State University \\ Raleigh, NC 27695 \\ ${ }^{2}$ King Abdullah University of Science and Technology \\ Clean Combustion Research Center \\ Thuwal, Saudi Arabia \\ ${ }^{3}$ Fuel Technology Division, R\&DC \\ Saudi Aramco \\ Dhahran, Saudi Arabia
}

*Corresponding Author

E-mail: tfang2@ncsu.edu

\begin{abstract}
In this work, the spray and auto-ignition characteristics of light naphtha (LN), primary reference fuels (PRF65, PRF95), Haltermann gasoline (CARB LEVIII, 10vol\% ethanol), and a gasoline surrogate were studied in an optically accessible constant volume combustion chamber. An outwardly opening hollow cone piezoelectric gasoline direct injection fuel injector was used. Five ambient temperatures from 650 to $950 \mathrm{~K}$ with a $75 \mathrm{~K}$ step were selected with a fixed ambient density of $3.5 \mathrm{~kg} / \mathrm{m}^{3}$, similar to the Spray G density defined by the engine combustion network
\end{abstract}


(ECN). Fuel auto-ignition was achieved with varying ignition delays for the five investigated fuels depending on the selected experimental conditions. Results show that the auto-ignition locations are randomly distributed in the combustion chamber. Differences in ignition delay times among the five fuels are more significant when the ambient temperature is lower than $750 \mathrm{~K}$. When the ambient temperature is lower than $750 \mathrm{~K}, \mathrm{PRF} 95$ always has the longest ignition delay and LN has the shortest. Ignition delays of the five fuels are almost identical when the ambient temperature exceeds $750 \mathrm{~K}$. Meanwhile, the five fuels have a similar spray front penetration length and spray angles before the occurrence of auto-ignition under all the investigated conditions.

\section{Keyword}

Gasoline direction injection; Auto-ignition; Naphtha; Gasoline surrogate; Constant volume combustion chamber

\section{Introduction}

Gasoline direct injection (GDI) has been considered to have the potential to satisfy the stringent emission requirements due to its advantages, and is becoming more popular in recent markets of spark-ignition (SI) engines. The incorporation of direct injection strategy into a sparkignition engine offers several improvements including enhanced fuel economy, higher compression ratio, reduced knocking tendency and improved transient responses. Compared with conventional port-fuel injection (PFI) engines, they can produce 5\% - 10\% higher miles per gallon (MPG) and lower greenhouse gas emissions [1-4]. Recent research has been focusing on employing new modeling methods [5] and new combustion concepts such as gasoline compression-ignition (GCI) with the potential of achieving diesel-like efficiencies and gasoline- 
like emissions. The use of gasoline fuels in compression-ignition combustion modes has shown encouraging results in both engine efficiency and emissions [6,7]. Two compression-ignition combustion modes are the most widely used in research [8-11]: premixed charge compression ignition (PCCI) and homogenous charge compression ignition (HCCI). PCCI engines were investigated in terms of fuel economy and NOx reduction in the 1990s by Aoyama and co-workers [8]. By using a single-cylinder light-duty compression ignition engine with PCCI combustion, Hildingsson et al. [9] investigated the necessity of high volatility of different fuels to achieve more premixed combustion with low NOx and soot emissions. HCCI is an alternative combustion approach for gasoline fuel compression ignition studies with higher combustion efficiency as well as low NOx and particulate emissions [10]. Experimental studies showed that stable GCI engine operation was achieved down to idle speed and load on a multi-cylinder compression ignition engine using gasoline [11]. GCI engines offer significant advantages with increased efficiency and reduced emissions compared to either conventional diesel compression ignition or gasoline spark ignition engines.

While gasolines with higher octane numbers can enable smooth and efficient spark ignition (SI) engines, low octane gasoline-like fuels might be more desirable in GCI engines. Compared to commercial gasoline and diesel fuels, blends of various refinery streams with low octane numbers (RON) in the 50-80 range have recently been considered attractive alternatives to provide suitable chemical characteristics (longer ignition delay than diesel) in GCI engines while lowering production cost and well-to-tank $\mathrm{CO}_{2}$ emissions. In addition, the utilization of the valuable highRON streams and octane boosters is not a part of the refining process of producing low-octane fuels [12,13]. Hao et al. [12] found that compared with the conventional pathway, the low-octane gasoline-GCI pathway leads to a $24.6 \%$ reduction in energy consumption and a $22.8 \%$ reduction 
in greenhouse gas (GHG) emissions. The research group in Saudi Aramco extensively investigated the combustion of various fuels in GCI engines [14-20]. Wang et al. [21]compared naphtha and commercial gasoline in the multiple premixed compression ignition (MPCI) mode. Their work demonstrated that naphtha MPCI can operate stably in a wide load range. With the same experimental system and combustion mode, they also found that the ignition delay of naphtha fuel is extended with the increase of injection pressure and the soot emission decreases at a high injection pressure with higher $\mathrm{CO}$ and $\mathrm{HC}$ emissions [22]. Manente et al. [23] studied the effect of gasoline-like fuels on the performance and emissions of an engine running in a partially premixed combustion (PPC) mode. Engines operating on lower octane number gasolines were also capable of running idle without increasing the inlet temperature [24]. A more optimized combustion chamber design was developed by Chang et al. [25] to improve the idle and light load combustion stability of naphtha fuels. The application of low cetane number (CN) naphtha fuels on diesel CI engines were evaluated by Won et al. [26] and Chang et al. [25] with different bowl and nozzle designs. Diesel CI engines can run with low CN naphtha fuels without compromising the vehicles' drivability, emissions, and power requirements. CN 35 naphtha fuels were recommended for their better robustness and lower $\mathrm{HC}$ and $\mathrm{CO}$ emissions. Zhang et al. [27] compared naphtha fuel and ultra-low sulfur diesel (ULSD) under both conventional and low temperature combustion modes. Naphtha fuels exhibited appreciably lower levels of soot compared to ULSD across the investigated engine operation range while maintaining a diesel equivalent fuel efficiency.

Generally speaking, naphtha is composed of $\mathrm{C} 5$ to $\mathrm{C} 11$ hydrocarbons and has a low research octane number (RON) value, roughly within the 40-70 range [28]. Naphtha requires less processing in the refinery than either gasoline or diesel [29], and the greenhouse gas emissions of the well to pump process are reduced from $18 \mathrm{~g} / \mathrm{MJ}$ fuel energy of gasoline to only $12 \mathrm{~g} / \mathrm{MJ}$ fuel 
energy for naphtha. Thus, there is an additional benefit in terms of the well-to-wheel $\mathrm{CO}_{2}$ emissions and overall energy consumed, and it can also be considered as a way of increasing the efficiency of a gasoline powertrain system [19]. The auto-ignition quality of a fuel at a given engine condition is described by an octane index defined as, $\mathrm{OI}=(1-\mathrm{K}) \mathrm{RON}+\mathrm{K} \mathrm{MON}$, where RON and MON are the Research and Motor Octane numbers respectively and K depends only on the engine design and operating conditions [30]. Approaches like direct injection, higher compression ratios, downsizing, and turbocharging can reduce the unburnt gas temperature for a given pressure and push the value of $\mathrm{K}$ downwards [31]. Fuels with high ignition resistance like gasoline has a significantly longer ignition delay and hence results in lower NOx and smoke for a given load compared to diesel fuels [32].

This study investigates the auto-ignition and spray characteristics of several gasolines and surrogates with a wide range of octane numbers. The fuels studied include light naphtha, primary reference fuels, Haltermann gasoline [33] and a gasoline surrogate [34]. The surrogate fuel for Haltermann gasoline was prepared using a non-linear constrained optimization scheme detailed in Ahmed et al [35]. The formulated surrogate matches several properties of Haltermann gasoline such as RON, MON, density, molecular weight, and volatility. These fuels and surrogates were investigated under different reactive spray conditions to measure various key spray and autoignition characteristics. By utilizing fuels with a wide range of octane numbers, more insights can be obtained on the feasibility of using low octane number fuels and naphtha fuels in gasoline compression ignition applications. The effects of fuel properties on auto-ignition and spray development before ignition can also be investigated, facilitating further advanced study on gasoline direct injection spray under elevated ambient conditions. 


\section{Methods}

Experiments were conducted in a constant volume combustion chamber with six ports under simulated engine auto-ignition combustion environments, as shown in Fig. 1. The advantage of utilizing a constant volume combustion chamber is that one or more key parameters can be controlled directly and precisely. This enables us to better study the effect of investigated parameters on the spray and combustion. The optical access was enabled by a quartz window installed on one port. Other ports were sealed by solid stainless steel plugs fitted with gas inlet, outlet, fuel injector, spark plug, pressure sensor, and other necessary hardware components. The inner diameter of the quartz window is $100 \mathrm{~mm}$, and the total chamber inner volume is $0.95 \mathrm{~L}$. More details of the chamber can be found in the previous publications [36-38]. An outwardly opening piezoelectric fuel injector was employed in this study. The fuel injector can produce a hollow cone spray. The spray shape is determined by the design of the nozzle exit without any swirl motion. It was controlled by a piezo injector driver from National Instruments, Inc. Fuel injection pressure was maintained at $10 \mathrm{MPa}(100 \mathrm{bar})$ by a gasoline common rail fuel system through all experiments. More details of the injector and fuel injection system can also be found in a previous publication [39]. Injection pulse duration for all investigated fuels was kept at $0.3 \mathrm{~ms}$ by using an external pulse generator. Temperature of both the chamber walls and fuel injector body were controlled at $90^{\circ} \mathrm{C}$. The fuel temperature at the injector tip was assumed similar to the body temperature due to the small amount of fuel injected. In order to generate an auto-ignition environment, a premixed combustion of lean acetylene-air mixture was employed prior to the fuel injection. Three different gases, acetylene, $\mathrm{O}_{2} / \mathrm{N}_{2}(50 \% / 50 \%)$ and dry air were used to formulate appropriate mixtures to obtain the desired ambient temperature and ambient oxygen concentration. Premixed reactants were ignited by a spark plug. In this study, the ambient oxygen concentration 
was set as $21 \%$ for all experiments before fuel injection. The compositions of the gas mixtures before and after the premixed acetylene combustion are listed in Table 1.

A Kistler 6041B transducer coupled with a Kistler 5004 charge amplifier was utilized to measure the transient chamber pressure during the entire combustion process, and the ambient temperature was calculated based on the pressure data using a corrected ideal gas law. A monochrome high-speed digital video camera (Phantom V4.3 camera from Vision Research Inc.) was used to capture both the spray and the auto-ignition processes. The camera was set at $5500 \mathrm{fps}$ with a resolution of $320 \times 312$ pixels for auto-ignition experiments. A $50 \mathrm{~mm}$ fixed focal length lens was used to collect signals. Camera exposure time and the aperture number $(\mathrm{F} \#)$ were selected based on the flame intensity under different ambient conditions for fuel auto-ignition experiments. The settings of exposure time and aperture number (F\#) are listed in Table 2. The auto-ignition combustion images for each condition were captured using the high speed camera and saved for later processing. Because the focus of the current study was to measure the ignition delay, therefore, the camera optical settings were adjusted for capturing early weak flames to identify the ignition locations and time delays. Although there exists flame intensity saturation during the late stage of combustion, the saturation has few effects on the flame development and shape for qualitative analysis. The time between the timing of the first flame image with detected ignition points and the start of fuel injection timing was used as the ignition delay time in this work. The average ignition delay time from five repeated measurements was used as the ignition delay for each condition. For the fuel spray experiments, the spray development during the fuel injection process was visualized by applying a Mie-scattering technique, and all the camera settings were kept the same (F\# 2.8, exposure time 37 um, resolution $128 \times 152$, and 21000 frames per second). In the current investigation, a pulse delay generator was used to enable an external trigger to synchronize 
the image capturing of the high-speed camera and the fuel injection. Rising edge of the triggering pulse was used for all the devices. Experiments were repeated five times for each case. In order to account for the uncertainty, data from the five runs were averaged, and the standard deviation was then calculated and reported.

For all the experiments, gas density in chamber was set as $3.5 \mathrm{~kg} / \mathrm{m}^{3}$ to be consistent with the non-reacting spray G condition defined in the engine combustion network (ECN) by Sandia National Laboratories [40]. While the ambient temperature and pressure condition changes for different cases, the ambient air density was kept the same throughout this study. Five different ambient temperatures ranged from $650 \mathrm{~K}$ to $950 \mathrm{~K}$ with a $75 \mathrm{~K}$ interval were selected, with the ambient equivalent pressures of 657, 733, 809, 884, and $960 \mathrm{kPa}$, respectively (listed in Table 2). Five different fuels were investigated: light naphtha (LN), two primary reference fuels (PRF65, PRF95), gasoline (Haltermann CARB LEV III) and gasoline surrogate (Haltermann surrogate).

The LN used in this study was obtained from Saudi Aramco, with an AKI (the average of the research octane number (RON) and the motor octane number (MON)) value of 64 . Conventionally, PRF is a binary mixture of iso-octane and n-heptane and is used as a surrogate for gasoline. PRF65, a blend of $65 \%$ iso-octane and $35 \% \mathrm{n}$-heptane by volume, was used here as a simple surrogate for LN. Similarly, PRF95 (95\% iso-octane and 5\% n-heptane by volume) was selected as a surrogate for the gasoline fuel. The Haltermann CARB LEV III RON 91 gasoline fuel was also used in this study. A gasoline surrogate was formulated, prepared, and tested along with other fuels. The surrogate fuel for Haltermann gasoline has been prepared using methodology described in Ahmed, et al. [35]. Haltermann gasoline is an oxygenated fuel ( $\sim 17 \mathrm{~mol} \%)$ with significant percentages paraffins ( $\sim 40 \mathrm{~mol} \%)$, aromatics ( $\sim 23 \mathrm{~mol} \%$ ) and naphthenes ( $\sim 16 \mathrm{~mol} \%)$. The selection of target properties for surrogate fuel is roughly based on conclusions of a recent 
study by Violi and co-workers [41] and our own works on gasoline surrogates [33,34,42-47], and includes $\mathrm{RON}, \mathrm{MON}$, density and $\mathrm{H} / \mathrm{C}$ ratio. The detailed hydrocarbon analysis (DHA) of fuel was conducted at Saudi Aramco in compliance with standards ASTM 6733 and 6730 [48] and the palette species for the surrogate fuel are chosen based on their structural similarities with species present in higher concentrations in the DHA. The surrogate palette consists of toluene, n-heptane, iso-octane, cyclopentane, 1,2,4-trimethylbenzene, and ethanol. The relevant values of the target properties were obtained from the DHA and certificate of acceptance from the fuel manufacturer. The blend of the surrogate palette was then optimized using the approach in Ahmed et al. [35] to match the target properties. The gasoline surrogate composition is shown in Table 3 . The properties of the five examined fuels are listed in Table 4 and the distillation curves are shown in Figure 2. As shown in Table 4, the fuel properties depend highly on the compositions, and heat of vaporization (HOV), fuel volatility and viscosity can change significantly. The vapor pressures can also correlate well with the flash points of the fuels. During the experiments, the fuel injection pressure and injection duration were kept constant. Due to the different densities of the fuels, the injected fuel mass quantities of gasoline, gasoline surrogate, LN, PRF65 and PRF95 are 10 mg, $9.85 \mathrm{mg}, 8.69 \mathrm{mg}, 9.13 \mathrm{mg}$ and $9.20 \mathrm{mg}$, respectively. Based on the spray $\mathrm{G}$ condition [40], the ambient gas density is $3.5 \mathrm{~kg} / \mathrm{m}^{3}$ and the oxygen concentration before fuel injection is $21 \%$ by volume for spray auto-ignition. The global average fuel/air mass ratio can be estimated as 0.003 (fuel lean condition) for the current experiment conditions. But due to the direct injection nature, the local fuel/air mass ratio can change significantly.

\section{Results and discussions}


In this section, auto-ignition characteristics of different fuels and fuel spray development before auto-ignition will be discussed. First of all, the auto-ignition combustion images are presented and discussed. For each set of images, locations of the injector, pressure transducer and the chamber view boundary are all the same, as marked in Figure 3. Fuel ignition delay, spray angle, spray front penetration length, and time-averaged spray front velocity were calculated and analyzed.

\subsection{Auto-ignition images}

In this study, fuel auto-ignition was observed for all the selected fuels under all the investigated ambient conditions. As mentioned above, experiments under each ambient condition were repeated five times. In this section, one set of images showing the typical features of the autoignition combustion of PRF65 under different ambient temperatures is presented in Figure 4 as an illustrative example. For each temperature, twenty consecutive images are selected to cover the ignition and combustion processes. Fuel type and image timing after the start of the injection trigger are marked on the upper left corner. The ambient temperature is noted at the bottom left corner. The related ambient pressure is also noted in the figure captions. The time marked on the images corresponds to each individual tests and may differ slightly from the averaged ignition delay values, since ignition delay results (presented in the next section) are an average of five experimental runs.

From PRF65 auto-ignition images, it can be seen that the location of the occurrence of auto-ignition is rather random in the combustion chamber, especially under lower ambient temperatures. For most of the experiments, the first detected flame pockets are located at the upperhalf region. Unlike HCCI combustion where fuel ignites almost simultaneously, a flame expansion process is observed in this study for gasoline-like fuels. The flame expansion depends heavily on 
the ambient conditions. Under a lower ambient temperature, flame spreads more slowly than under a higher ambient temperature. Once the ambient temperature is higher than $800 \mathrm{~K}$, the flame shifts towards the left and shows a more elliptical shape, which is closer to the original spray cone shape. This is due to the shorter ignition delay under higher ambient temperature conditions, and could be better explained in combination with the discussion of ignition delay in later sections.

\subsection{Ignition delay}

Ignition delay in this work is defined as the time interval between the start of the injection trigger and the occurrence of auto-ignition. The camera and the injector were triggered simultaneously by a pulse generator in this study. The timing of auto-ignition occurrence is defined to be the first frame where combustion flame appears. Therefore, the ignition delay could be obtained from the injection timing and captured high speed video images. The final ignition delay value of each fuel under each investigated condition is the average of the five repeats of experiments with the same experimental settings, and the standard derivation is calculated to evaluate the variation of the results, as show in Table 5. It is seen from the ignition delay measurements that the ignition delay times range between $0.887 \mathrm{~ms}$ and $12.265 \mathrm{~ms}$. The reported ignition delay times are all longer than the injection duration $(0.3 \mathrm{~ms})$ used in this study. As will be discussed in the next section, the measured physical injection process ends at about $0.43 \mathrm{~ms}$ after the injection trigger pulse. Therefore, a partially-premixed combustion mode is expected here and the mixture stratification is dependent on the ambient temperatures and pressures. At low ambient temperatures, the injected fuel has more time to mix with the air and hence the stratification is lower at the time of autoignition. The stratification level is significantly higher when operating at high ambient temperatures because of the relatively short time between the end of injection and the autoignition of the fuel/air mixture. In addition, the short mixing time helps 
explain why flames generally shift to the left towards the injector nozzle and becomes more elliptical with increasing ambient temperature. The uncontrolled spray development and droplet vaporization after the end of injection, as well as the fuel vapor turbulent interaction with the ambient air, may be the key reasons for the random auto-ignition locations and flame shape. Finally, no obvious spray diffusion combustion is observed even for the $950 \mathrm{~K}$ ambient temperature condition due to the relatively short fuel injection duration. Comparison of auto-ignition flame images of all the five fuels under the $650 \mathrm{~K}$ and $950 \mathrm{~K}$ conditions are presented in Figure 5 and Figure 6. It is found that flame characteristics discussed above could also be found for the other four fuels in this study. Flames structures share almost the same patterns for all five fuels at different ambient temperatures.

The measured ignition delay times for all the fuels at all the conditions are presented in Figure 7. As expected, the ignition delay times of all the examined fuels decrease when increasing the ambient temperatures and pressures. This is due to the higher reactivity of the fuels at higher temperatures. However, the decrease in ignition delay times as a function of ambient temperature can be divided into two distinct regimes. The first regime is for temperatures between $650 \mathrm{~K}$ and $800 \mathrm{~K}$ where the decrease of the ignition delay times is a strong function of temperature. The second regime is for temperatures higher than $800 \mathrm{~K}$ where the ignition delay times of all the fuels collapse to similar values and their decreasing rates become almost negligible when further increasing the ambient temperature.

To further analyze the discussed trends, the homogeneous gas-phase ignition delay times of PRF65, PRF95 and the gasoline surrogate are calculated at $800 \mathrm{kPa}(8 \mathrm{bar})$ and equivalence ratios of $0.5,1.0$, and 2.0 with CHEMKIN software using the mechanism in Ref [49]. The homogeneous gas-phase ignition delay times for the three fuels under different ambient 
temperatures from $650 \mathrm{~K}$ to $1200 \mathrm{~K}$ are shown in Figure 8. It should be noted that these simulations are intended only to qualitatively understand the observed experimental trends, and quantitative agreement is not the objective. A comparison between the absolute values of the measured and calculated ignition delay times cannot be made here because they were obtained with different physical boundary conditions. As mentioned earlier, the experimental ignition delay times, by definition, have spray injection, breakup, evaporation, mixing and autoignition embedded in them. However, the calculated homogenous ignition delay times are from a 0-D homogeneous reactor where the vapor phase fuel and air are perfectly premixed awaiting for autoignition. In general, the calculated ignition delay times are significantly higher than the measured ones. There are many factors that can explain these differences, however, the main one is the equivalence ratio at which autoignition occurs. Figure 8 shows that the ignition delay time is a strong function of equivalence ratio and richer mixtures are more reactive. In fact, the calculated ignition delay time of PRF65 at $\phi=2$ and $\mathrm{T}=650 \mathrm{~K}$ is shorter than the measured one for the same fuel at the same temperature conditions. In the experiments, the fuel-air mixing is highly stratified because of injection, breakup, evaporation, and mixing. We therefore believe that the experimental autoignition is mostly initiated at locally rich fuel-air pockets leading to a significantly lower ignition delay times compared to the calculated ones at lean and stoichiometric conditions. This is consistent with the phenomenological model for diesel spray combustion by Dec [50], which concluded that ignition occurs at locally rich equivalence ratio regions (e.g., $\phi=2-4)$.

As can be seen from Figure 8, the ignition delay times of the three fuels are stronger functions of temperatures at lower than $750 \mathrm{~K}$ temperatures. However, a clear negative temperature coefficient (NTC) behavior is overserved at temperatures between $750 \mathrm{~K}$ and $900 \mathrm{~K}$ where the ignition delay time dependency on temperature is weak. Moreover, the similarities in the ignition 
delay times presented in Fig. 7 at temperatures higher than $800 \mathrm{~K}$ can also be explained by the presented homogeneous ignition delay times where the ignition timings of the three fuels are similar in the NTC region. These observations are in line with the findings from recently reported experimental ignition delay time measurements of LN and its surrogates [49]. Comparing the ignition delay among the five investigated fuels, PRF95 always has the longest ignition delay and LN has the shortest ignition delay when the ambient temperature is lower than $750 \mathrm{~K}$. Gasoline surrogate has a slightly shorter ignition delay than neat gasoline, and as expected, the ignition delay of PRF65 is lower than PRF95.

The fuel reactivity, defined as the homogenous ignition delay time, is not the only controlling parameter when it comes to the ignition delay times of reacting sprays. Many other physical and chemical fuel properties affect the autoignition. For example, the octane numbers (RON and MON) are very important indicators of the fuel's reactivity. Higher ON indicates lower reactivity and hence more resistance to autoignition under different operating conditions. The correlation between AKI (average between RON and MON) of the tested fuels and the reported ignition delay times is obvious at low temperatures. LN has the lowest AKI and PRF95 has the highest AKI. These correspond to the shortest and longest reported ignition delay times at $650 \mathrm{~K}$ for LN and PRF95, respectively. However, the ignition delay times cannot be explained by only looking at the ON (or AKI) because the gasoline fuel and its surrogate have similar AKI but different ignition delay times at $650 \mathrm{~K}$. The equivalence ratio-temperature distribution is a key determining factor in compression-ignition engines [51-54] and like any compression-ignition combustion system, the ignition delay times of reacting sprays are dependent on the local temperature and equivalence ratio distribution in the constant volume combustion chamber. Therefore, any fuel properties that affect the equivalence ratio-temperature distribution should be 
considered when analyzing the trends observed here. Below is a list of the properties that might affect the mixing and hence combustion in the presented spray setup:

- Boiling curve: the distillation curve of the fuel is an indicator of the evaporation of the fuel and hence affects its mixing with the surrounding air.

- Density: the spray exit velocity is inversely proportional to the square root of the fuel density. The spray exit velocity affects the spray penetration, breakup, and mixing with air.

- Heat of vaporization (HOV): the temperature of the evaporated fuel is inversely proportional to the heat of vaporization of the fuel. This directly affects the temperature at which the fuel is distributed at.

- Lower heating value (LHV): the lower heating value is a measure of the energy contained in a fuel. This energy density affects the low-temperature heat release rates and hence the main combustion event.

- Viscosity: the droplet breakup is inversely proportional to the viscosity of the fuel. The droplet breakup affects its evaporation and hence mixing.

- Surface tension: the droplet breakup is inversely proportional to the surface tension of the fuel.

These fuel properties need to be considered altogether when trying to analyze the similarities and differences between the ignition delay times of fuels with similar reactivity (RON, MON and AKI). It was shown earlier that the physical and chemical properties of fuels with the same octane ratings affect their combustion in gasoline compression ignition mode [53-55].

PRF65 and PRF95 have very similar physical and chemical properties except their ON. The differences between their ignition delay times is attributed to the $30 \mathrm{RON}$ difference between these two fuels. LN and PRF65 have similar ON but different ignition delay times. The differences 
in the ignition delay times are caused by other physical and chemical properties of both fuels. The density of LN is lower than that of PRF65 and hence the spray exit velocity of LN is higher. This higher velocity will facilitate the droplets breakup and the mixing with air resulting in overall leaner mixtures. Lean mixtures are less reactive than rich ones and hence LN should have had longer ignition delay times compared to PRF65 if density was the only contributing parameter. However, it is not the case here and other parameters such as the boiling characteristics are affecting the ignition delay times of LN and PRF65. LN has much lower final boiling point (FBP) compared to PRF65 and hence the injected fuel quickly evaporates and mixes with the air close to the injector. This sequence of events results in richer fuel/air pockets that are located closer to the injector when compared with the PRF65 case. These richer pockets cause the ignition delay times to be shorter than those of PRF65. This finding is in agreement to what was recently observed in engine simulations and experiments using LN and PRF65 surrogate [52-54]. PRF 65 has significantly higher reactivity compared to the gasoline fuel and its multi-component surrogate, however, it has longer ignition delay times at low temperatures (Fig. 7). The density differences between PRF65 and the gasoline fuel as well as its surrogate are noticeable and certainly plays an important role in the observed trend. The gasoline fuel and its surrogate have higher densities compared to PRF65 and hence the spray exit velocity is lower resulting in richer fuel/air pockets. These localized rich/air mixtures control the ignition event and partially explain why the more reactive PRF65 has ignition delay times that are longer than those of RON91 fuels. In addition to the differences in densities, the gasoline fuel and its surrogate has wider boiling curve compared to PRF65 and hence some of the light components from the gasoline fuel and its surrogate evaporate before PRF65 and cause rich fuel/air pockets to form in the vicinity of the injector. The boiling range effect also contributes towards aiding the RON91 fuels to have lower ignition delay 
times. Interestingly, the contributions of different factors yielded shorter ignition delay times for RON91 fuels despite PRF65 has 26 RON advantage. Finally, the ignition delay times of the gasoline surrogate are close to those of the gasoline fuel except at $650 \mathrm{~K}$ where the gasoline surrogate is slightly more reactive. This again can be explained by the small differences in the boiling characteristics. However, the gasoline surrogate generally successfully reproduces the ignition quality of the real gasoline fuel.

\subsection{Fuel spray characteristics before ignition}

In order to further analyze the resulting auto-ignition process and the variation in the ignition delay of different fuels, macroscopic spray features of each fuel before auto-ignition were studied to help understand the spray characteristics under combusting environments. Generally speaking, the fuel spray angle and the fuel front penetration length can be used to evaluate physical spray characteristics. Therefore, the time averaged fuel spray angle, spray front penetration length and spray penetration velocity were calculated and discussed. The fuel spray angle is defined as the averaged angle between the two spray edges at pre-determined locations near the injector tip at a time after the start of fuel injection [56]. In this study, the effective locations are selected from the nozzle orifice to the spray front. The spray front penetration length is defined as the average distance between the entire spray front and the nozzle exit plane. The spray penetration velocity is calculated based on the spray front penetration length results. In order to calculate the spray angle and the spray front penetration length, the two spray edges and the spray front were first detected and marked with colored lines using a Matlab code developed in-house with the same threshold for all transient images in each single injection. The electronic injection pulse duration was set as $0.3 \mathrm{~ms}$. For all the experiments, the physical injection process ended at around $0.43 \mathrm{~ms}$ after the start of injection trigger (ASOIT) due to the delay caused by opening and closing injector nozzle. 
To ensure result consistency, the ambient conditions were kept similar to the fuel auto-ignition experiments. In other words, the presented spray images exactly represent the spray development before the occurrence of fuel auto-ignition under investigated ambient conditions. Since the spray liquid signal becomes negligible right after the end of injection, the spray angle and spray front penetration length calculation were limited to the time from first spray image timing to the end of fuel injection.

A set of spray images of PRF65 under different ambient temperatures are selected as an example, as shown in Figure 9. For each image, the two spray edges and the spray front were marked red, blue and green, respectively. The ambient temperature ranges from $650 \mathrm{~K}$ to $950 \mathrm{~K}$ with a constant in-chamber gas density of $3.5 \mathrm{~kg} / \mathrm{m}^{3}$. It has been discussed in [56] that a higher ambient pressure lead to a shorter spray penetration length and stronger edge vortex at downstream under the same ambient temperature. In this work, it turns out that the spray under different ambient temperature conditions has almost the same structure and development for the same fuel. Downstream vortices occur at similar locations for all the investigated conditions. The only obvious difference is that liquid signal decreases with increasing ambient temperature caused by increasing fuel evaporation rates. This indicates that the ambient gas density might be the dominant factor that determines the spray structure. In addition, the spray structure comparison of the five fuels at $650 \mathrm{~K}$ and $950 \mathrm{~K}$ is show in Figure 10 and Figure 11. It is seen that the differences in the fuel spray structure and development among all the investigated fuels are small.

\subsubsection{Time-averaged spray angle}

The time-averaged spray angle of each fuel was calculated. In this study, the time interval from the start of the injection trigger to the end of the injection was used for calculating the timeaveraged spray angle. The time-averaged spray angle of each fuel under different ambient 
temperatures is shown in Figure 12. The effect of the ambient temperature on the time-averaged spray angle can be then presented. It is found that for each fuel the time averaged spray angle decreases with increasing ambient temperature, which is believed to be caused by a faster fuel evaporation rate under a higher ambient temperature environment. Under higher ambient temperatures the droplets at the periphery of the cone-shaped spray turn into vapor faster, leading to a smaller spray angle. Comparing the time-averaged spray angle among the five selected fuels, PRF65 and PRF95 always have larger spray angles than the other three fuels for all investigated ambient conditions, as show in Figure 13. The difference of the time averaged spray angle among different fuels also becomes smaller with increasing ambient temperature. Meanwhile, it should be noted that the variation of the time-averaged spray angle is quite small among different fuels. All the time averaged spray angle results are around $100^{\circ}$, and the maximum difference is less than

\section{$3^{\circ}$. 3.3.2 Transient spray penetration length and front penetration velocity}

The spray front penetration length of the five fuels under different ambient temperatures were calculated and are shown in Figure 14. For each fuel, a higher ambient temperature leads to a shorter penetration length during the entire injection process, and the penetration length difference at different ambient temperatures increases with time. Three factors may contribute to this phenomenon. First, as mentioned above, a higher ambient temperature directly relates to a higher ambient pressure. A higher ambient pressure generates faster momentum exchange, which could lead to a larger drag force experienced by the moving fuel droplets. As a result, the spray penetration is more prohibited with increasing ambient temperature. Secondly, a higher back pressure reduces the pressure difference between the common rail system (10 MPa (100 bar) injection pressure in this study) and the in-chamber environment. Based on Bernoulli's equation, the flow exit velocity is proportional to the root square of the pressure difference. Therefore, the 
flow exit velocity under a higher ambient temperature/higher ambient pressure condition is slightly lower than flow velocity under a lower ambient temperature/lower ambient pressure, which also affects the spray penetration length. The third and the most important factor is the faster evaporation for spray at higher ambient temperature, which causes the reduction in spray penetration. However, it should be noted that even though the tendency of the spray front penetration length at different ambient temperatures is clear and consistent for all the five fuels, the absolute variation in the penetration length at different ambient temperatures is quite small. In order to better understand the effect of fuel types on the spray characteristics, the spray penetration length was compared among the five investigated fuels, as shown in Figure 15. It turns out that the five fuels have similar spray front penetration length for the entire injection process at each ambient condition. No clear correlation is found on the spray front penetration length among these fuels. The similar time-averaged spray angle (as discussed earlier) and spray front penetration length results of different fuels may indicate that the effect of fuel physical properties may not be the dominant factor in affecting the spray structure and development, where the injection momentum and geometric parameters of the injector might play more important roles. But the difference in fuel properties should be significant in affecting the microscopic spray structure such as fuel atomization and droplet size distribution.

The time-averaged spray penetration velocity was calculated based on the spray front penetration length results, as presented in Figure 16. Similar to the time-averaged spray angle result, a lower time-averaged spray penetration velocity is observed at a higher ambient temperature for all the five fuels. However, the effect of the ambient temperature weighs differently for different fuels. For example, the penetration velocity of PRF95 decreases very slow when the ambient temperature is lower than $750 \mathrm{~K}$, then drops much faster when the ambient 
temperature is higher than $750 \mathrm{~K}$, while the penetration velocity of $\mathrm{LN}$ behaves in an opposite manner. For the time-averaged spray penetration velocity among the five selected fuels, no definite pattern can be found under a certain ambient temperature.

\section{Summary}

This work investigates the auto-ignition of sprays of different fuels from a piezoelectric fuel injector under different ambient temperatures with a prescribed ambient air density of 3.5 $\mathrm{kg} / \mathrm{m}^{3}$. Both the combustion and spray characteristics were measured and analyzed under autoignition conditions. Important findings can be summarized as follows:

1. Fuel auto-ignition was observed with noticeable ignition delay for the five investigated fuels under all the selected experimental conditions. Locations of the occurrence of auto-ignition are randomly distributed in the combustion chamber. Occasionally, more than one auto-ignition occurrence locations could take place in an experimental test.

2. For all the experiments, the injection event ends at $0.43 \mathrm{~ms}$ after trigger, and ignition delay ranges from $106 \%$ to $2750 \%$ longer than injection event. For each fuel, a longer ignition delay is found under a lower ambient temperature condition. The ignition delay decreases rapidly with increasing ambient temperature when the ambient temperature is lower than $750 \mathrm{~K}$, but the ignition delay decreasing rate becomes smaller once the ambient temperature exceeds $750 \mathrm{~K}$.

3. The octane number plays an important role when the ambient temperature is low. When the ambient temperature is lower than $750 \mathrm{~K}$, PRF95 always has the longest ignition delay, whileLN has the shortest ignition delay which is about $50 \%$ of that of PRF95. Gasoline surrogate has slightly shorter ignition delay than neat gasoline. Ignition delay of five fuels are very similar when the ambient temperature exceeds $750 \mathrm{~K}$. 
4. Five fuels have similar spray front penetration length development and spray angles before the occurrence of auto-ignition under all the investigated conditions. The effect of fuel physical properties may not be the dominant factor in affecting the spray structure and development, where the injection momentum and geometric parameters of the injector might play more important roles.

\section{Acknowledgement}

This research was supported in part by the Saudi Aramco R\&D Center through the Clean Combustion Research Center of the King Abdullah University of Science and Technology under the FUELCOM program. Any opinions, findings, and conclusions or recommendations expressed in this material are those of the author(s) and do not necessarily reflect the views of the funding agencies.

\section{References}

[1] Geng P, Zhang H. Combustion and emission characteristics of a direct-injection gasoline engine using the MMT fuel additive gasoline. Fuel 2015;144:380-7. doi:10.1016/j.fuel.2014.12.064.

[2] Imoehl W, Gestri L, Maragliulo M, Del-Frate L, Klepatsch M, Wildeson R. A DOE approach to engine deposit testing used to optimize the design of a gasoline direct injector seat and orifice. SAE Int J Fuels Lubr 2012;5:1078-95. doi:10.4271/2012-01-1642.

[3] Überall A, Otte R, Eilts P, Krahl J. A literature research about particle emissions from engines with direct gasoline injection and the potential to reduce these emissions. Fuel 2015;147:203-7. doi:10.1016/j.fuel.2015.01.012. 
[4] Zhu R, Hu J, Bao X, He L, Lai Y, Zu L, et al. Tailpipe emissions from gasoline direct injection (GDI) and port fuel injection (PFI) vehicles at both low and high ambient temperatures. Environmental Pollution 2016;216:223-34.

doi:10.1016/j.envpol.2016.05.066.

[5] Rahimi-Gorji M, Ghajar M, Kakaee A-H, Domiri Ganji D. Modeling of the air conditions effects on the power and fuel consumption of the SI engine using neural networks and regression. J Braz Soc Mech Sci Eng 2017;39:375-84. doi:10.1007/s40430-016-0539-1.

[6] Kalghatgi G, Hildingsson L, Johansson B. Low NOx and Low Smoke Operation of a Diesel Engine Using Gasolinelike Fuels. J Eng Gas Turbines Power 2010;132:092803-092803-9. doi:10.1115/1.4000602.

[7] Hildingsson L, Kalghatgi G, Tait N, Johansson B, Harrison A. Fuel octane effects in the partially premixed combustion regime in compression ignition engines. Warrendale, PA: SAE Technical Paper; 2009. doi:10.4271/2009-01-2648.

[8] Aoyama T, Hattori Y, Mizuta J 'ichi, Sato Y. An experimental study on premixed-charge compression ignition gasoline engine. Warrendale, PA: SAE Technical Paper; 1996. doi:10.4271/960081.

[9] Hildingsson L, Johansson B, Kalghatgi GT, Harrison AJ. Some effects of fuel autoignition quality and volatility in premixed compression ignition engines. SAE Int J Engines 2010;3:440-60. doi:10.4271/2010-01-0607.

[10] Sjöberg M, Dec JE. Influence of fuel autoignition reactivity on the high-load limits of HCCI engines. SAE International Journal of Engines 2009;1:39-58. 
[11] Kolodziej C, Kodavasal J, Ciatti S, Som S, Shidore N, Delhom J. Achieving stable engine operation of gasoline compression ignition using 87 AKI gasoline down to idle.

Warrendale, PA: SAE Technical Paper; 2015. doi:10.4271/2015-01-0832.

[12] Hao H, Liu F, Liu Z, Zhao F. Compression ignition of low-octane gasoline: Life cycle energy consumption and greenhouse gas emissions. Applied Energy 2016;181:391-8. doi:10.1016/j.apenergy.2016.08.100.

[13] Compression Ratio and Derived Cetane Number Effects on Gasoline Compression Ignition Engine Running with Naphtha Fuels n.d. http://papers.sae.org/2014-01-1301/ (accessed June 28, 2016).

[14] Viollet Y, Chang J, Kalghatgi G. Compression ratio and derived cetane number effects on gasoline compression ignition engine running with naphtha fuels. SAE Int J Fuels Lubr 2014;7:412-26. doi:10.4271/2014-01-1301.

[15] Badra JA, Sim J, Elwardany A, Jaasim M, Viollet Y, Chang J, et al. Numerical Simulations of Hollow-Cone Injection and Gasoline Compression Ignition Combustion With Naphtha Fuels. J Energy Resour Technol 2016;138:052202-052202. doi:10.1115/1.4032622.

[16] Zhang Y, Voice A, Tzanetakis T, Traver M, Cleary D. An evaluation of combustion and emissions performance with low cetane naphtha fuels in a multicylinder heavy-duty diesel engine. J Eng Gas Turbines Power 2016;138:102805-102805-10. doi:10.1115/1.4032879.

[17] Chang J, Kalghatgi G, Amer A, Viollet Y. Enabling high efficiency direct injection engine with naphtha fuel through partially premixed charge compression ignition combustion. Warrendale, PA: SAE Technical Paper; 2012. doi:10.4271/2012-01-0677. 
[18] Chang J, Viollet Y, Alzubail A, Abdul-Manan AFN, Arfaj AA. Octane-on-demand as an enabler for highly efficient spark ignition engines and greenhouse gas emissions improvement. Warrendale, PA: SAE Technical Paper; 2015. doi:10.4271/2015-01-1264.

[19] Chang J, Viollet Y, Amer A, Kalghatgi G. Fuel economy potential of partially premixed compression ignition (ppci) combustion with naphtha fuel. Warrendale, PA: SAE Technical Paper; 2013. doi:10.4271/2013-01-2701.

[20] Viollet Y, Abdullah M, Alhajhouje A, Chang J. Characterization of high efficiency octaneon-demand fuels requirement in a modern spark ignition engine with dual injection system. Warrendale, PA: SAE Technical Paper; 2015. doi:10.4271/2015-01-1265.

[21] Wang B, Wang Z, Shuai S, Yang H, Wang J. Combustion and emission characteristics of Multiple Premixed Compression Ignition (MPCI) fuelled with naphtha and gasoline in wide load range. Energy Conversion and Management 2014;88:79-87. doi:10.1016/j.enconman.2014.08.045.

[22] Wang B, Wang Z, Shuai S, Xu H. Combustion and emission characteristics of Multiple Premixed Compression Ignition (MPCI) mode fuelled with different low octane gasolines. Applied Energy 2015;160:769-76. doi:10.1016/j.apenergy.2015.01.115.

[23] Manente V, Johansson B, Tunestal P, Cannella W. Effects of different type of gasoline fuels on heavy duty partially premixed combustion. SAE Int J Engines 2009;2:71-88. doi:10.4271/2009-01-2668.

[24] Manente V, Zander C-G, Johansson B, Tunestal P, Cannella W. An advanced internal combustion engine concept for low emissions and high efficiency from idle to max load using gasoline partially premixed combustion. Warrendale, PA: SAE Technical Paper; 2010. doi:10.4271/2010-01-2198. 
[25] Chang J, Kalghatgi G, Amer A, Adomeit P, Rohs H, Heuser B. Vehicle demonstration of naphtha fuel achieving both high efficiency and drivability with euro6 engine-out nox emission. SAE Int J Engines 2013;6:101-19. doi:10.4271/2013-01-0267.

[26] Won HW, Bouet A, Duffour F, Francqueville L. Naphtha fuel on a light duty single cylinder compression ignition engine with two different compression ratios. Warrendale, PA: SAE Technical Paper; 2016. doi:10.4271/2016-01-2302.

[27] Zhang Y, Kumar P, Traver M, Cleary D. Conventional and low temperature combustion using naphtha fuels in a multi-cylinder heavy-duty diesel engine. SAE Int J Engines 2016;9:1021-35. doi:10.4271/2016-01-0764.

[28] Kalghatgi G, Gosling C, Wier M. The outlook for transport fuels: Part 1. Petroleum Technology Quarterly 2016.

[29] Wang M, Lee H, Molburg J. Allocation of energy use in petroleum refineries to petroleum products. Int J LCA 2004;9:34-44. doi:10.1007/BF02978534.

[30] Risberg P, Kalghatgi G, Ångstrom H-E. Auto-ignition quality of gasoline-like fuels in HCCI engines. Warrendale, PA: SAE Technical Paper; 2003. doi:10.4271/2003-01-3215.

[31] Kalghatgi GT. Auto-Ignition Quality of Practical Fuels and Implications for Fuel Requirements of Future SI and HCCI Engines. Warrendale, PA: SAE Technical Paper; 2005. doi:10.4271/2005-01-0239.

[32] Richter M, Engström J, Franke A, Aldén M, Hultqvist A, Johansson B. The influence of charge inhomogeneity on the HCCI combustion process. Warrendale, PA: SAE Technical Paper; 2000. doi:10.4271/2000-01-2868. 
[33] Lee C, Ahmed A, Nasir EF, Badra J, Kalghatgi G, Sarathy SM, et al. Autoignition characteristics of oxygenated gasolines. Combustion and Flame 2017;186:114-28. doi:10.1016/j.combustflame.2017.07.034.

[34] Sarathy SM, Farooq A, Kalghatgi GT. Recent progress in gasoline surrogate fuels. Progress in Energy and Combustion Science 2018;65:67-108. doi:10.1016/j.pecs.2017.09.004.

[35] Ahmed A, Goteng G, Shankar VSB, Al-Qurashi K, Roberts WL, Sarathy SM. A computational methodology for formulating gasoline surrogate fuels with accurate physical and chemical kinetic properties. Fuel 2015;143:290-300. doi:10.1016/j.fuel.2014.11.022.

[36] Wu Z, Jing W, Zhang W, Roberts WL, Fang T. Narrow band flame emission from dieseline and diesel spray combustion in a constant volume combustion chamber. Fuel 2016;185:829-46. doi:10.1016/j.fuel.2016.08.022.

[37] Jing W, Wu Z, Roberts WL, Fang T. Spray combustion of biomass-based renewable diesel fuel using multiple injection strategy in a constant volume combustion chamber. Fuel 2016;181:718-28. doi:10.1016/j.fuel.2016.05.039.

[38] Jing W, Wu Z, Roberts WL, Fang T. Effects of fuel quantity on soot formation process for biomass-based renewable diesel fuel combustion. J Eng Gas Turbines Power 2017;139:102803-102803-5. doi:10.1115/1.4036292.

[39] Wang L, Badra JA, Roberts WL, Fang T. Characteristics of spray from a GDI fuel injector for naphtha and surrogate fuels. Fuel 2017;190:113-28. doi:10.1016/j.fuel.2016.11.015.

[40] Engine Combustion Network | "spray G” Operating Condition n.d. https://ecn.sandia.gov/gasoline-spray-combustion/target-condition/spray-g-operatingcondition/ (accessed October 25, 2018). 
[41] Kim D, Martz J, Violi A. Effects of fuel physical properties on direct injection spray and ignition behavior. Fuel 2016;180:481-96. doi:10.1016/j.fuel.2016.03.085.

[42] Javed T, Ahmed A, Lovisotto L, Issayev G, Badra J, Sarathy SM, et al. Ignition studies of two low-octane gasolines. Combustion and Flame 2017;185:152-9. doi:10.1016/j.combustflame.2017.07.006.

[43] Selim H, Mohamed SY, Hansen N, Sarathy SM. Premixed flame chemistry of a gasoline primary reference fuel surrogate. Combustion and Flame 2017;179:300-11. doi:10.1016/j.combustflame.2017.02.008.

[44] Chen B, Togbé C, Selim H, Dagaut P, Sarathy SM. Quantities of Interest in Jet Stirred Reactor Oxidation of a High-Octane Gasoline. Energy Fuels 2017;31:5543-53. doi:10.1021/acs.energyfuels.6b03193.

[45] Ahmed A, Waqas M, Naser N, Singh E, Roberts W, Chung S, et al. Compositional effects of gasoline fuels on combustion, performance and emissions in engine. SAE Int J Fuels Lubr 2016;9:460-8. doi:10.4271/2016-01-2166.

[46] Chen B, Togbé C, Wang Z, Dagaut P, Sarathy SM. Jet-stirred reactor oxidation of alkanerich FACE gasoline fuels. Proceedings of the Combustion Institute 2017;36:517-24. doi:10.1016/j.proci.2016.05.040.

[47] Sarathy M, Kukkadapu G, Mehl M, Javed T, Ahmed A, Naser N, et al. Compositional effects on the ignition of FACE gasolines 2016. doi:10.1016/j.combustflame.2016.04.010.

[48] Nadkarni R. Guide to ASTM test methods for the analysis of petroleum products and lubricants, 2nd edition. 2ND ed. ASTM International; 2007. doi:10.1520/MNL44-2ND-EB. 
[49] Javed T, Nasir EF, Ahmed A, Badra J, Djebbi K, Beshir M, et al. Ignition delay measurements of light naphtha: A fully blended low octane fuel. Proceedings of the Combustion Institute 2017;36:315-22. doi:10.1016/j.proci.2016.05.043.

[50] Dec J.E. A Conceptual Model of DI Diesel Combustion Based on Laser-Sheet Imaging*, (1997). doi:10.4271/970873.

[51] Badra J, Elwardany A, Sim J, Viollet Y, Im H, Chang J. Effects of in-cylinder mixing on low octane gasoline compression ignition combustion. Warrendale, PA: SAE Technical Paper; 2016. doi:10.4271/2016-01-0762.

[52] Atef N, Badra J, Jaasim M, Im HG, Sarathy SM. Numerical investigation of injector geometry effects on fuel stratification in a GCI engine. Fuel 2018;214:580-9. doi:10.1016/j.fuel.2017.11.036.

[53] Badra J, Viollet Y, Elwardany A, Im HG, Chang J. Physical and chemical effects of low octane gasoline fuels on compression ignition combustion. Applied Energy 2016;183:1197208. doi:10.1016/j.apenergy.2016.09.060.

[54] Badra J, Bakor R, AlRamadan A, Almansour M, Sim J, Ahmed A, et al. Standardized gasoline compression ignition fuels matrix. Warrendale, PA: SAE Technical Paper; 2018. doi:10.4271/2018-01-0925.

[55] Naser N, Jaasim M, Atef N, Chung SH, Im HG, Sarathy SM. On the effects of fuel properties and injection timing in partially premixed compression ignition of low octane fuels. Fuel 2017;207:373-88. doi:10.1016/j.fuel.2017.06.048.

[56] Hung DLS, Harrington DL, Gandhi AH, Markle LE, Parrish SE, Shakal JS, et al. Gasoline fuel injector spray measurement and characterization - a new SAE J2715 recommended practice. SAE Int J Fuels Lubr 2008;1:534-48. 


\section{List of Tables and Figures}

Table 1 Gas compositions before and after the premixed combustion

Table 2. The F\# and exposure time for the auto-ignition test conditions

Table 3. Gasoline surrogate composition

Table 4 Selected fuel properties of investigated fuels

Table 5 Ignition delay of gasoline, gasoline surrogate, LN, PRF65 and PRF95 at different

ambient temperatures (*: Ambient pressures are determined by the ideal gas law under $3.5 \mathrm{~kg} / \mathrm{m}^{3}$ density)

Figure 1. Experimental system: 1. fuel injector, 2. exhaust line, 3. chamber body, 4. quartz window, 5.plug/window retainer, 6. pressure transducer, 7. intake line, 8. metal plug, 9. spark plug, 10. Combustion chamber, 11. high speed camera

Figure 2. Distillation curves of the five investigated fuels

Figure 3. Locations of injector, pressure transducer and chamber view boundary

Figure 4. Auto-ignition images of PRF65 under different ambient temperatures and pressures with a constant density of $3.5 \mathrm{~kg} / \mathrm{m} 3$

Figure 5. Comparison of auto-ignition images of five fuels under $650 \mathrm{~K}$ and $657 \mathrm{kPa}$ ambient conditions with a density of $3.5 \mathrm{~kg} / \mathrm{m} 3$

Figure 6. Comparison of auto-ignition images of five fuels under $950 \mathrm{~K}$ and $960 \mathrm{kPa}$ ambient conditions with a density of $3.5 \mathrm{~kg} / \mathrm{m} 3$

Figure 7. Ignition delay of the five investigated fuels at the five tested ambient temperatures and pressures: $650 \mathrm{~K}(657 \mathrm{kPa}), 725 \mathrm{~K}(733 \mathrm{kPa}), 800 \mathrm{~K}(809 \mathrm{kPa}), 875 \mathrm{~K}(884 \mathrm{kPa})$, and $950 \mathrm{~K}$ $(960 \mathrm{kPa})$

Figure 8. Calculated ignition delay time of the three surrogate fuels (PRF65, PRF95, and Gasoline surrogate) under different temperatures and an ambient pressure of $800 \mathrm{kPa}$ ( $8 \mathrm{bar}$ ): (a) equivalence ratio of 0.5 ; (b) equivalence ratio of 1.0 ; and (c) equivalence ratio of 2.0

Figure 9. PRF65 spray images before ignition under different ambient temperatures and pressures with a constant density of $3.5 \mathrm{~kg} / \mathrm{m} 3$ 
Figure 10. Comparison of fuel spray before auto-ignition of five fuels at $650 \mathrm{~K}$ and $657 \mathrm{kPa}$ ambient conditions with a density of $3.5 \mathrm{~kg} / \mathrm{m} 3$

Figure 11. Comparison of fuel spray before auto-ignition of five fuels at $950 \mathrm{~K}$ and $960 \mathrm{kPa}$ ambient conditions with a density of $3.5 \mathrm{~kg} / \mathrm{m} 3$

Figure 12. Time averaged spray angle of five fuels under different ambient temperatures Figure 13. Comparison of time averaged spray angle among five fuels under different ambient temperatures

Figure 14. Spray front penetration length of five fuels under different ambient temperatures Figure 15. Comparison of spray front penetration length among five fuels at: (a) $650 \mathrm{~K}$, (b) $950 \mathrm{~K}$ Figure 16. Comparison of spray front penetration velocity among five fuels (a) and under different temperatures (b) 


\begin{tabular}{|c|c|c|c|c|c|c|c|}
\hline States & $\begin{array}{c}\mathbf{C}_{2} \mathbf{H}_{2} \\
(\mathbf{V} \%)\end{array}$ & $\begin{array}{c}\mathbf{O}_{2} \\
(\mathbf{V} \%)\end{array}$ & $\begin{array}{c}\mathbf{C O}_{2} \\
(\mathbf{V} \%)\end{array}$ & $\begin{array}{c}\mathbf{H}_{2} \mathbf{O} \\
(\mathbf{V} \%)\end{array}$ & $\begin{array}{c}\mathbf{N}_{2} \\
(\mathbf{V} \%)\end{array}$ & $\begin{array}{c}\mathbf{M W} \\
(\mathbf{g} / \mathbf{m o l})\end{array}$ & $\begin{array}{c}\text { Density } \\
\left(\mathbf{k g} / \mathbf{m}^{\mathbf{3}}\right)\end{array}$ \\
\hline $\begin{array}{c}\text { Before premixed } \\
\text { combustion }\end{array}$ & 4.1 & 44.2 & 0 & 0 & 51.1 & 28.6 & 3.5 \\
\hline $\begin{array}{c}\text { After premixed } \\
\text { combustion }\end{array}$ & 0 & 21 & 9.8 & 4.9 & 64.3 & 29.9 & 3.5 \\
\hline
\end{tabular}

Table 1 Gas compositions before and after the premixed combustion

\begin{tabular}{|c|c|c|c|c|c|}
\hline & \multicolumn{5}{|c|}{ F\# / Exposure time (us) } \\
\hline Ambient temperature (K) & $\mathbf{6 5 0}$ & $\mathbf{7 2 5}$ & $\mathbf{8 0 0}$ & $\mathbf{8 7 5}$ & $\mathbf{9 5 0}$ \\
\hline *Ambient pressure (kPa) & $\mathbf{6 5 7}$ & $\mathbf{7 3 3}$ & $\mathbf{8 0 9}$ & $\mathbf{8 8 4}$ & $\mathbf{9 6 0}$ \\
\hline Gasoline & $2.8 / 178$ & $2.8 / 178$ & $2.8 / 120$ & $2.8 / 120$ & $2.8 / 120$ \\
\hline Gasoline surrogate & $2.8 / 178$ & $2.8 / 178$ & $8.0 / 178$ & $11 / 178$ & $11 / 178$ \\
\hline LN & $2.8 / 178$ & $2.8 / 50$ & $11 / 5$ & $11 / 5$ & $11 / 5$ \\
\hline PRF65 & $2.8 / 166$ & $2.8 / 160$ & $8 / 20$ & $8 / 1$ & $11 / 5$ \\
\hline PRF95 & $2.8 / 166$ & $2.8 / 160$ & $5.6 / 20$ & $5.6 / 1$ & $11 / 5$ \\
\hline
\end{tabular}

Table 2. The F\# and exposure time for the auto-ignition test conditions

\begin{tabular}{|l|r|r|}
\hline \multicolumn{1}{|c|}{ Species } & Wt (\%) & mol (\%) \\
\hline Toluene & 6.593 & 6.602 \\
\hline n-Heptane & 14.286 & 13.159 \\
\hline iso-Octane & 35.165 & 28.413 \\
\hline Cyclopentane & 13.187 & 17.352 \\
\hline 1,2,4-trimethylbenzene & 21.978 & 16.870 \\
\hline Ethanol & 8.791 & 17.604 \\
\hline
\end{tabular}

Table 3. Haltermann gasoline surrogate composition

\begin{tabular}{|l|l|l|l|l|l|}
\hline & \multicolumn{1}{|c|}{ PRF65 } & \multicolumn{1}{|c|}{ PRF95 } & \multicolumn{1}{|c|}{ LN } & \multicolumn{1}{|c|}{ Gasoline } & \multicolumn{1}{c|}{$\begin{array}{c}\text { Gasoline } \\
\text { surrogate }\end{array}$} \\
\hline Density $\left(\mathbf{g m} / \mathbf{c m}^{\mathbf{3}}\right)$ & 687 & 692 & 654 & 755 & 743 \\
\hline Boiling point $\left.\mathbf{(}^{\circ} \mathbf{C}\right)$ & $98-99$ & $98-99$ & $50-73$ & $41-176$ & $71-165$ \\
\hline Viscosity (N-s/m2) & $4.32 \mathrm{E}-04$ & $4.53 \mathrm{E}-04$ & $2.74 \mathrm{E}-04$ & $4.95 \mathrm{E}-04$ & $5.62 \mathrm{E}-04$ \\
\hline Surface tension (N/m) & $1.87 \mathrm{E}-02$ & $1.83 \mathrm{E}-02$ & $1.63 \mathrm{E}-02$ & $2.15 \mathrm{E}-02$ & $2.23 \mathrm{E}-02$ \\
\hline HOV (J/kg) & $3.30 \mathrm{E}+05$ & $3.14 \mathrm{E}+05$ & $3.63 \mathrm{E}+05$ & $5.01 \mathrm{E}+05$ & $4.55 \mathrm{E}+05$ \\
\hline LHV (MJ/kg) & 44.40 & 44.32 & 45.08 & 41.92 & 41.78 \\
\hline RON & 65 & 95 & 65 & 91 & 91 \\
\hline MON & 65 & 95 & 63 & 83 & 83 \\
\hline AKI & 65 & 95 & 64 & 87 & 87 \\
\hline $\begin{array}{l}\text { Vapor Pressure at 300 } \\
\text { K (kPa) }\end{array}$ & 7.00 & 7.16 & 50.20 & 32.62 & 12.70 \\
\hline
\end{tabular}

Table 4. Selected fuel properties of investigated fuels 


\begin{tabular}{|c|c|c|c|c|c|}
\hline & \multicolumn{5}{|c|}{ Ignition delay (ms) } \\
\hline Ambient temperature (K) & $\mathbf{6 5 0}$ & $\mathbf{7 2 5}$ & $\mathbf{8 0 0}$ & $\mathbf{8 7 5}$ & $\mathbf{9 5 0}$ \\
\hline *Ambient pressure (kPa) & $\mathbf{6 5 7}$ & $\mathbf{7 3 3}$ & $\mathbf{8 0 9}$ & $\mathbf{8 8 4}$ & $\mathbf{9 6 0}$ \\
\hline Gasoline & 7.10 & 2.31 & 1.15 & 0.87 & 0.71 \\
\hline Gasoline surrogate & 5.76 & 2.08 & 1.25 & 1.10 & 0.89 \\
\hline LN & 4.83 & 2.00 & 1.39 & 1.17 & 0.99 \\
\hline PRF65 & 10.06 & 3.01 & 1.65 & 1.16 & 0.95 \\
\hline PRF95 & 12.27 & 3.81 & 1.17 & 1.37 & 1.09 \\
\hline
\end{tabular}

Table 5. Ignition delay of gasoline, gasoline surrogate, LN, PRF65 and PRF95 at different ambient temperatures (*: Ambient pressures are determined by the ideal gas law under $3.5 \mathrm{~kg} / \mathrm{m}^{3}$ density)

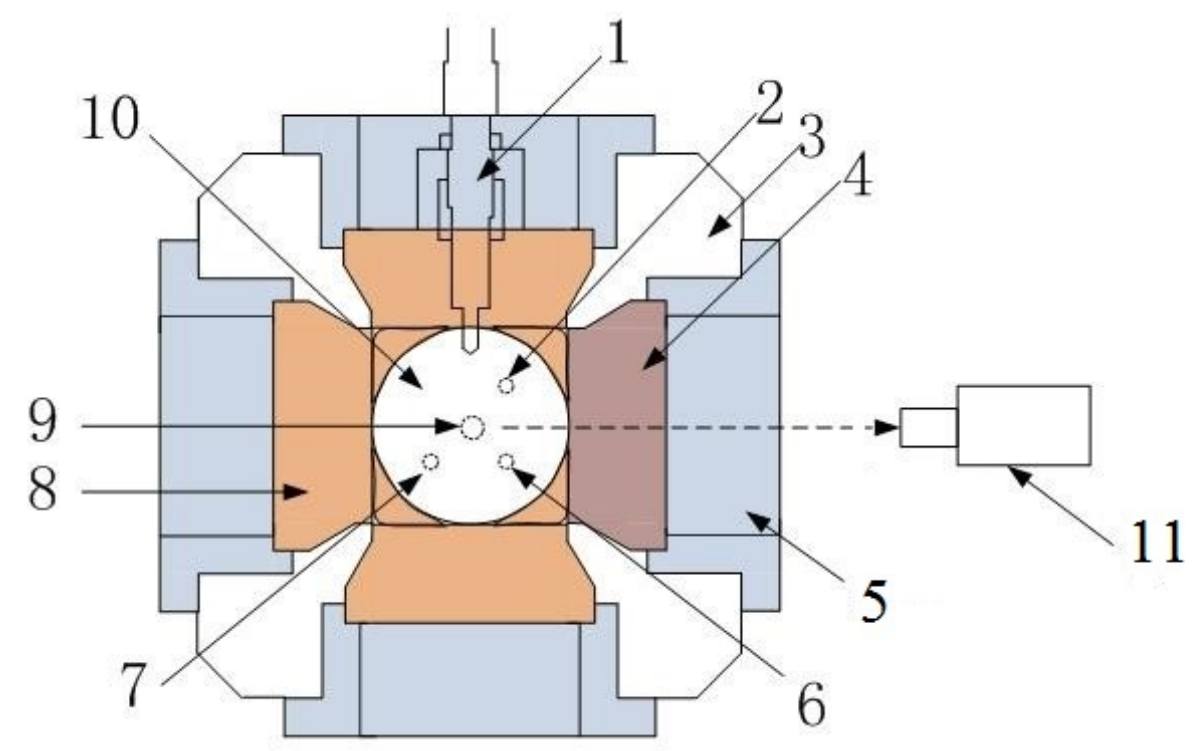

Figure 1. Experimental system: 1. fuel injector, 2. exhaust line, 3. chamber body, 4. quartz window, 5.plug/window retainer, 6. pressure transducer, 7. intake line, 8. metal plug, 9. spark plug, 10. Combustion chamber, 11. high speed camera 


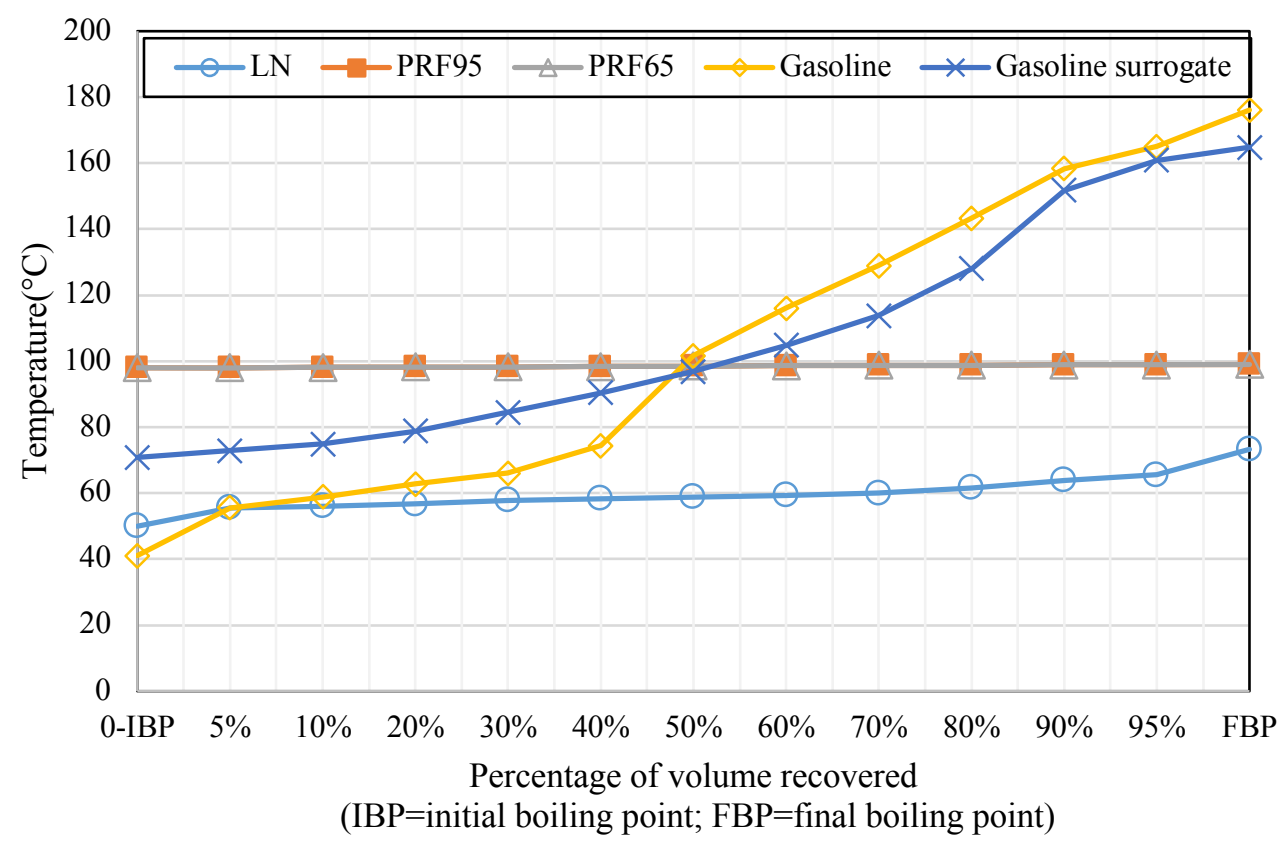

Figure 2. Distillation curves of the five investigated fuels



Figure 3. Locations of injector, pressure transducer and chamber view boundary 


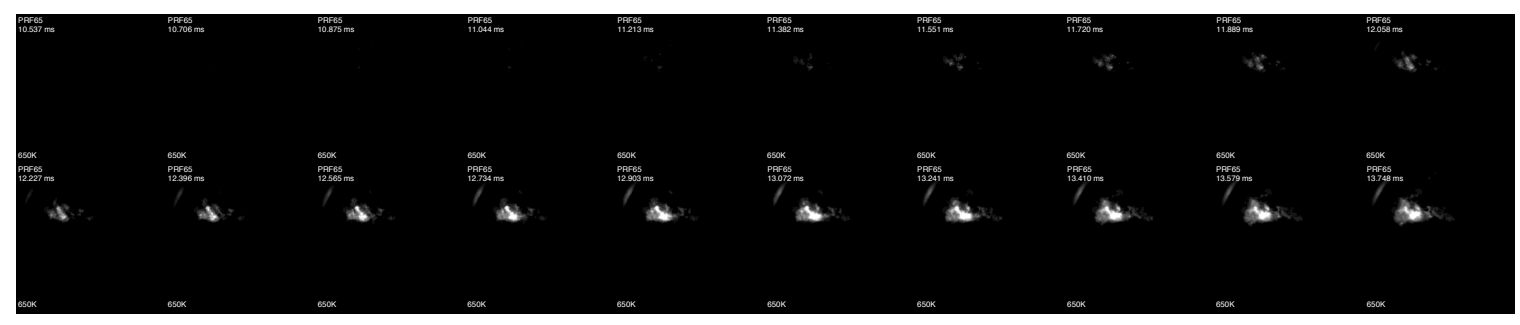

(a) PRF65 at $650 \mathrm{~K}$ and $657 \mathrm{kPa}$

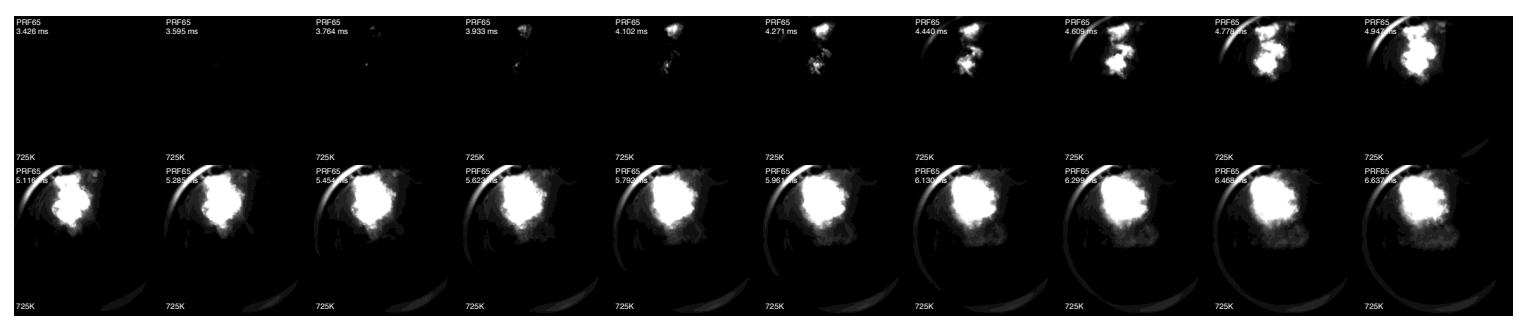

(b) PRF65 at $725 \mathrm{~K}$ and $733 \mathrm{kPa}$

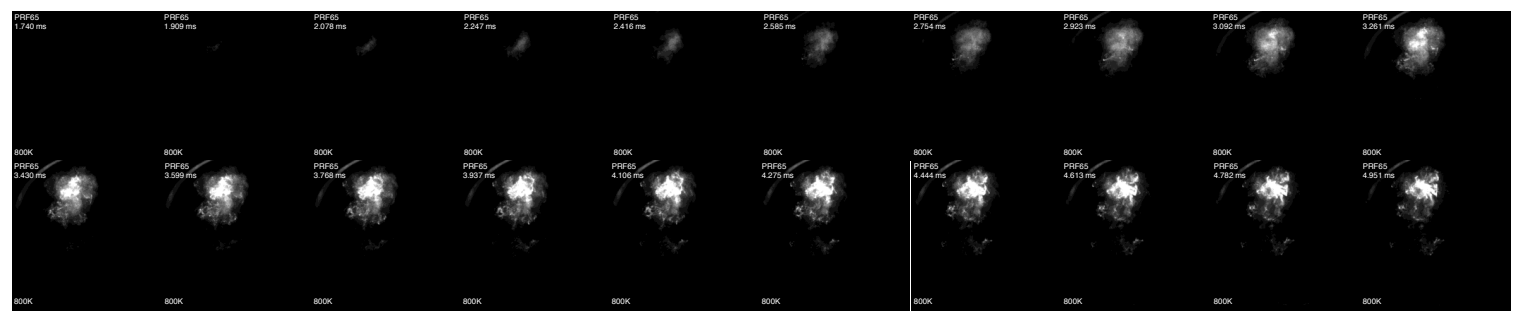

(c) PRF65 at $800 \mathrm{~K}$ and $809 \mathrm{kPa}$

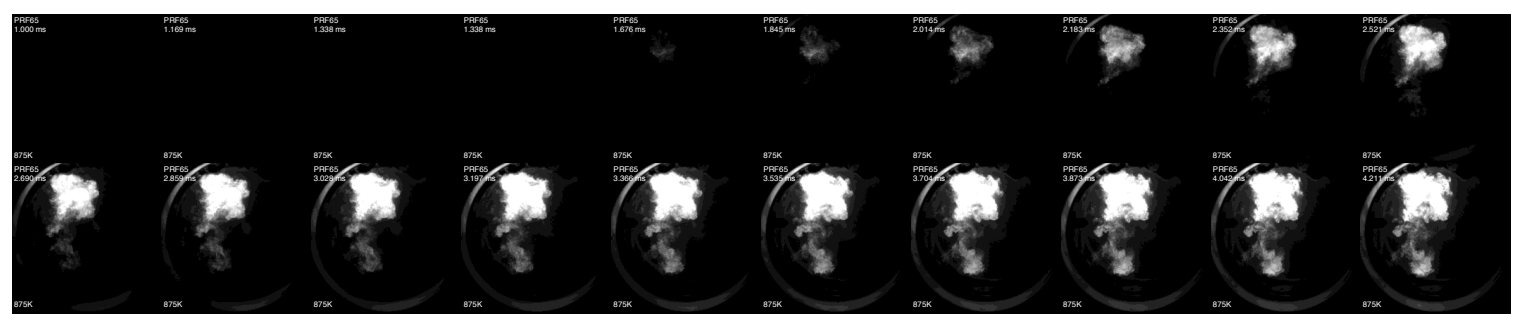

(d) PRF65 at $875 \mathrm{~K}$ and $884 \mathrm{kPa}$

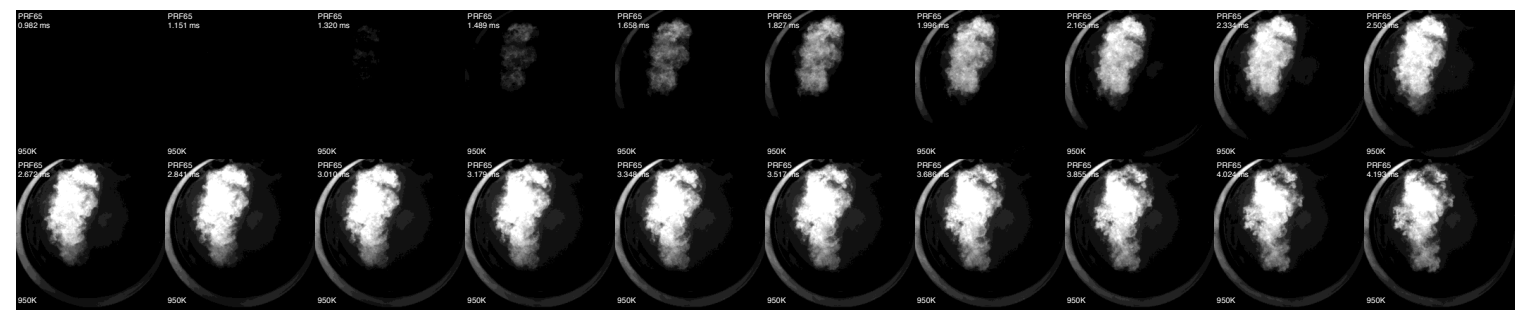

(e) PRF65 at $950 \mathrm{~K}$ and $960 \mathrm{kPa}$

Figure 4. Auto-ignition images of PRF65 under different ambient temperatures and pressures with a constant density of $3.5 \mathrm{~kg} / \mathrm{m}^{3}$ 


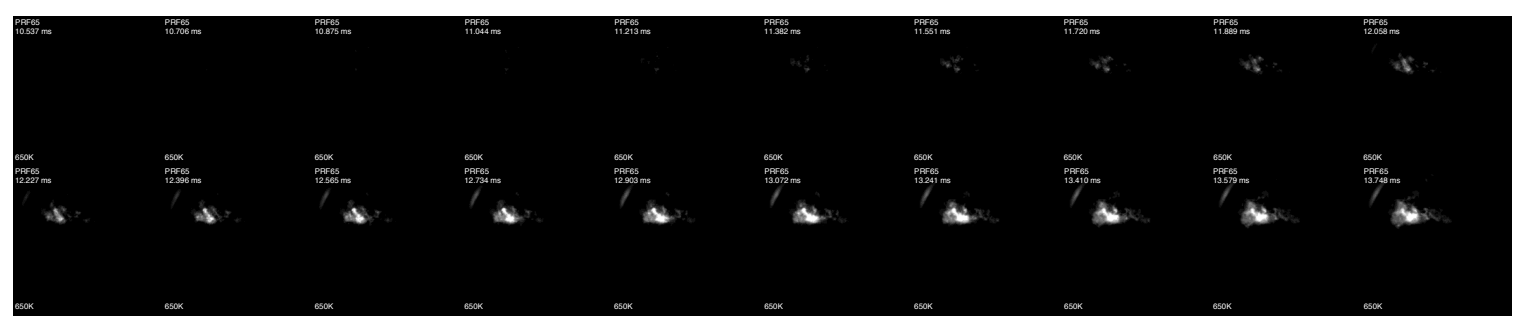

(A) PRF 65

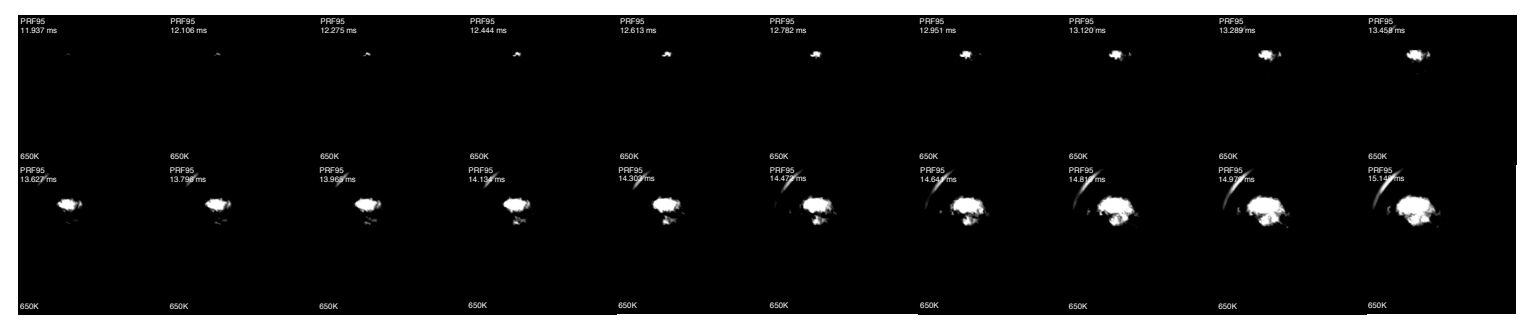

(B) PRF95

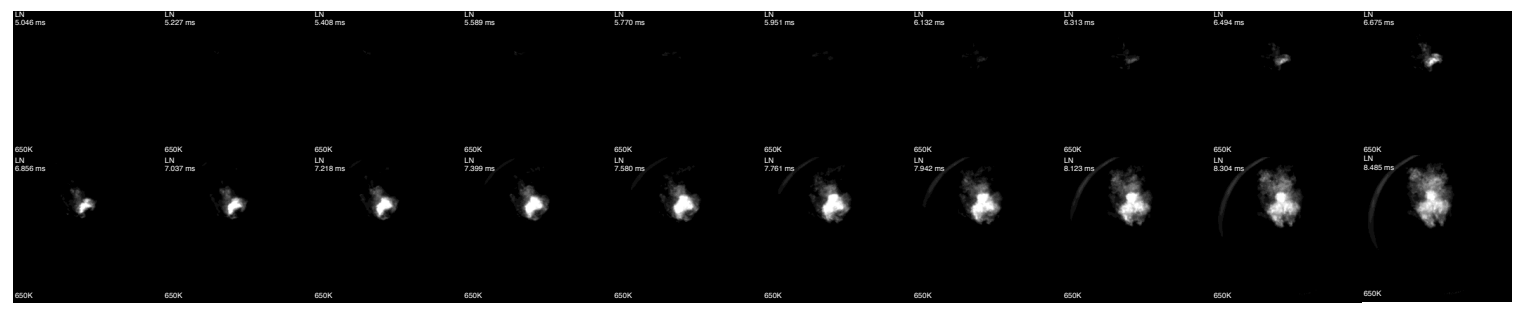

(C) $\mathrm{LN}$

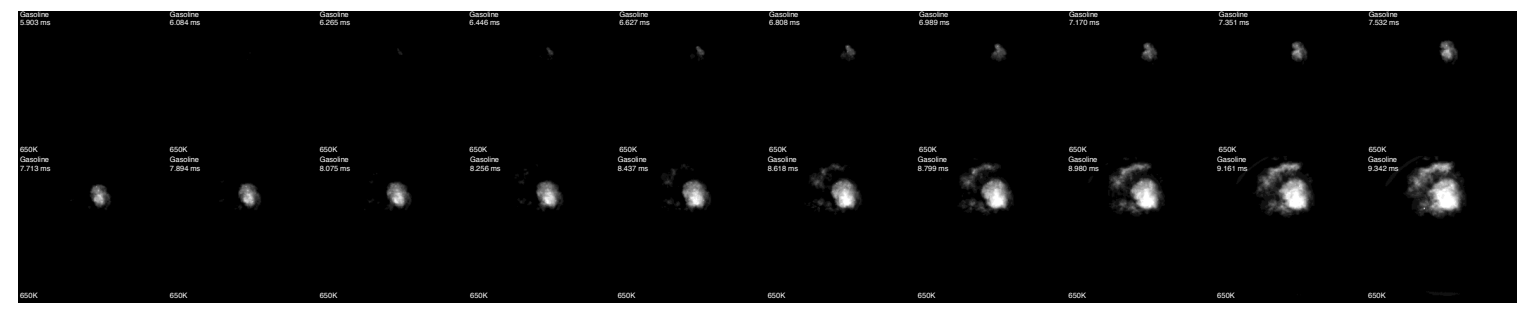

(D) Gasoline

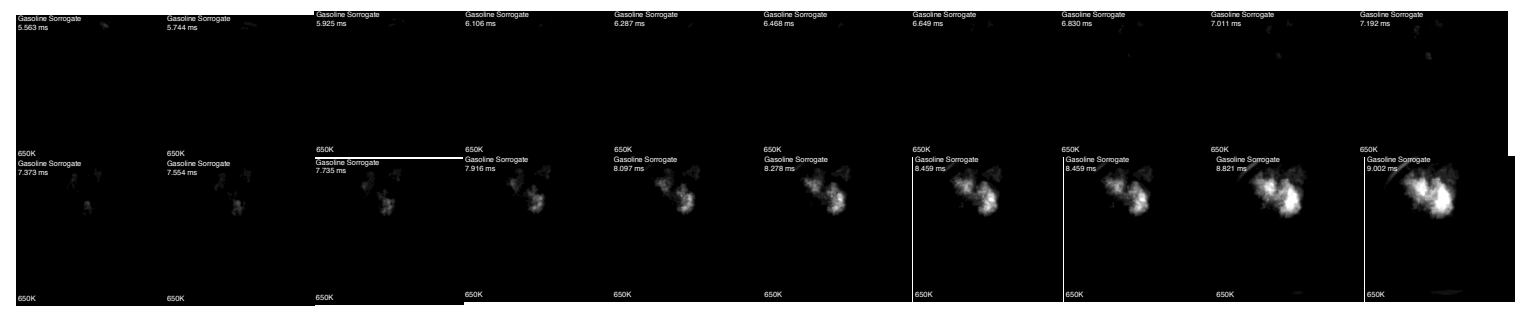

(E) Gasoline surrogate

Figure 5. Comparison of auto-ignition images of five fuels under $650 \mathrm{~K}$ and $657 \mathrm{kPa}$ ambient conditions with a density of $3.5 \mathrm{~kg} / \mathrm{m}^{3}$ 


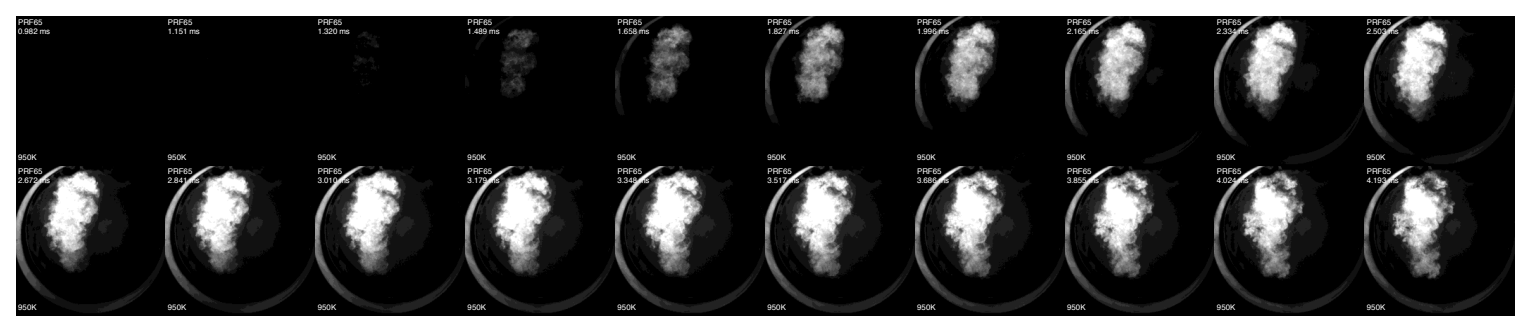

(A) PRF65

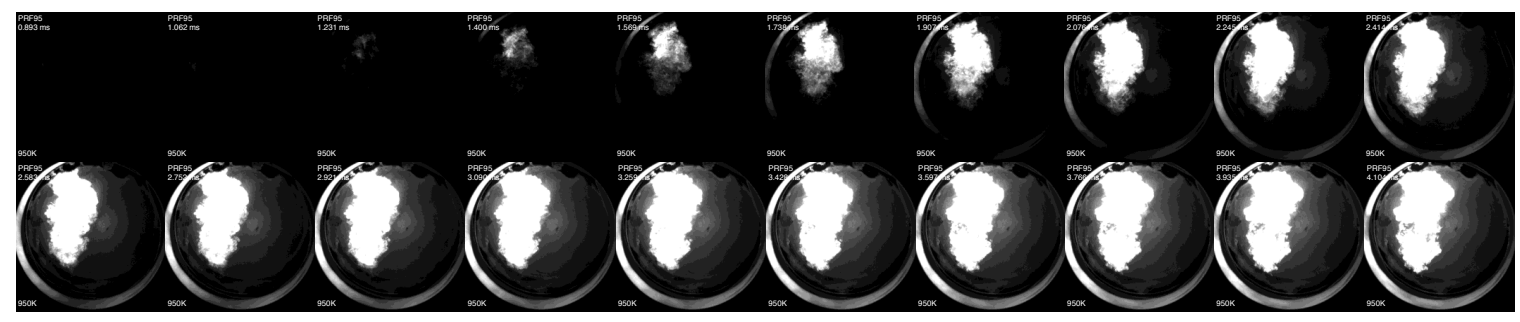

(B) PRF95

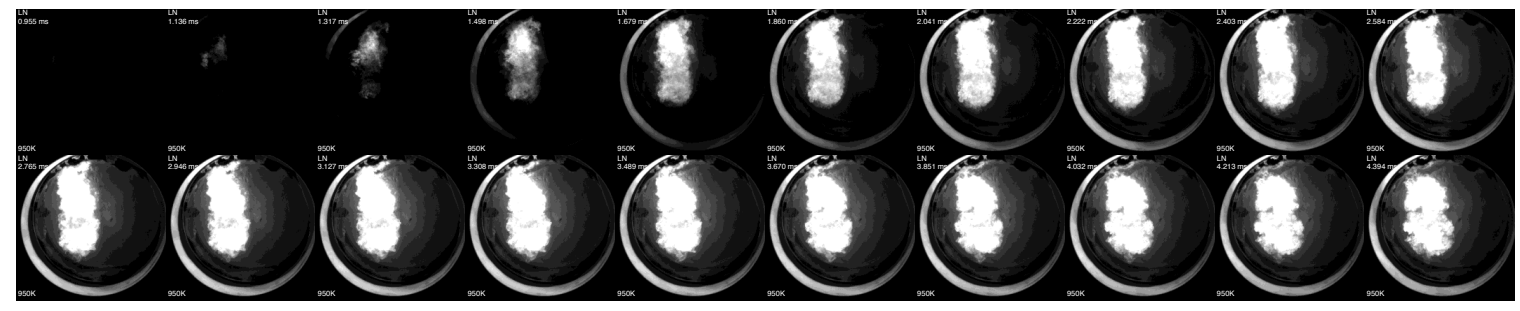

(C) LN

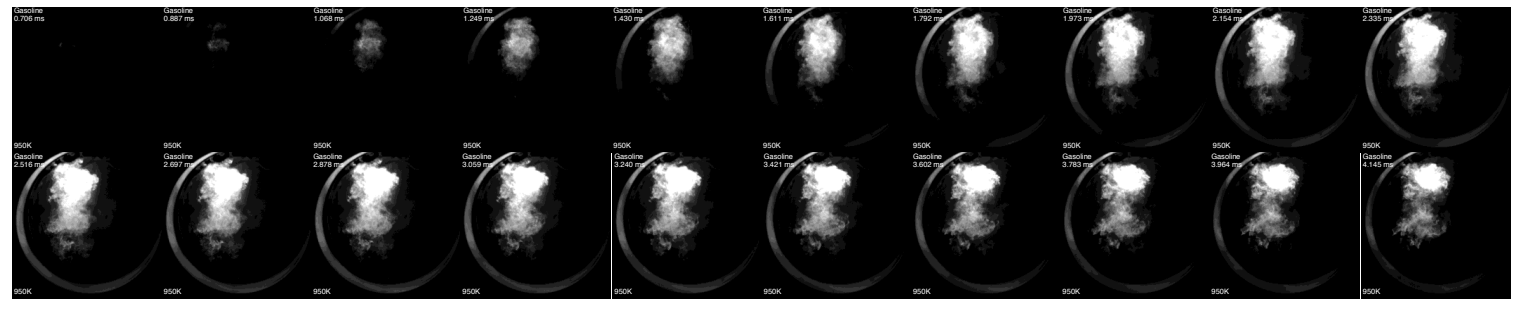

(D) Gasoline



(E) Gasoline surrogate

Figure 6. Comparison of auto-ignition images of five fuels under $950 \mathrm{~K}$ and $960 \mathrm{kPa}$ ambient conditions with a density of $3.5 \mathrm{~kg} / \mathrm{m}^{3}$ 


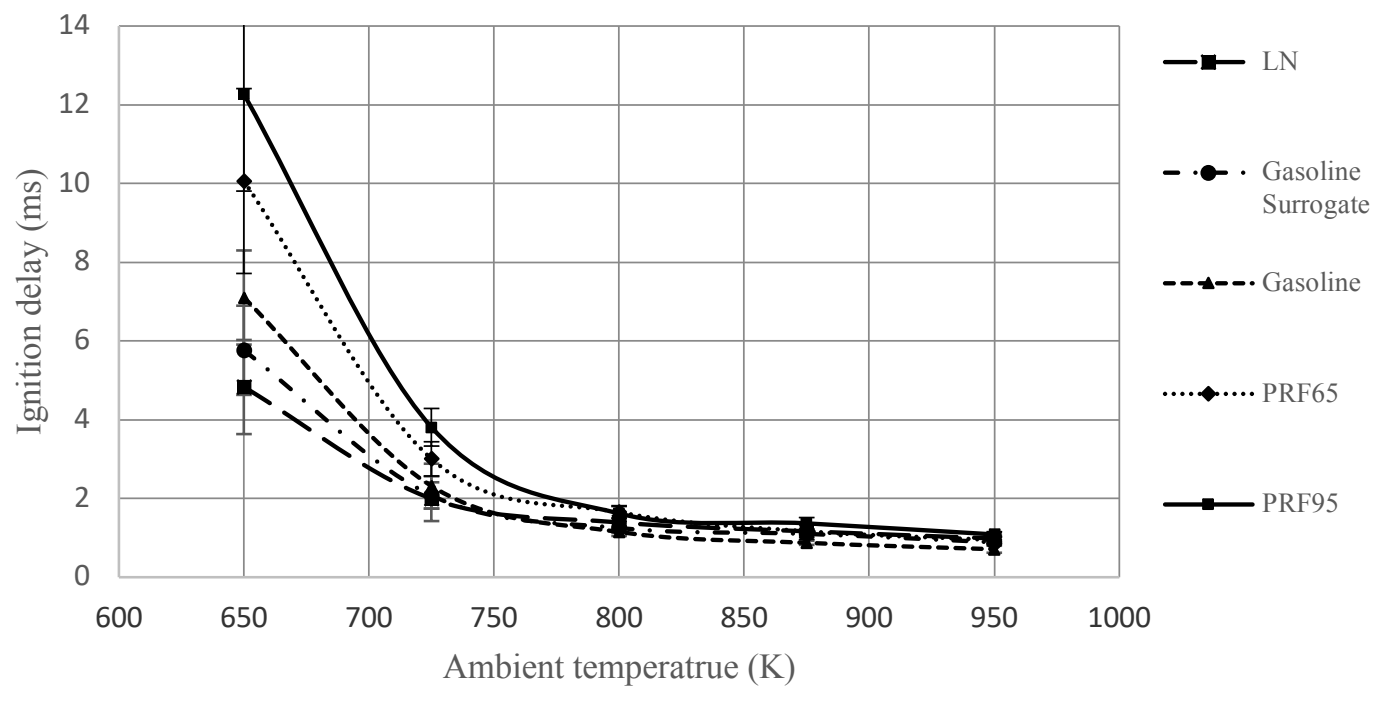

Figure 7. Ignition delay of the five investigated fuels at the five tested ambient temperatures and pressures: $650 \mathrm{~K}(657 \mathrm{kPa}), 725 \mathrm{~K}(733 \mathrm{kPa}), 800 \mathrm{~K}(809 \mathrm{kPa}), 875 \mathrm{~K}(884 \mathrm{kPa})$, and $950 \mathrm{~K}$ $(960 \mathrm{kPa})$ 

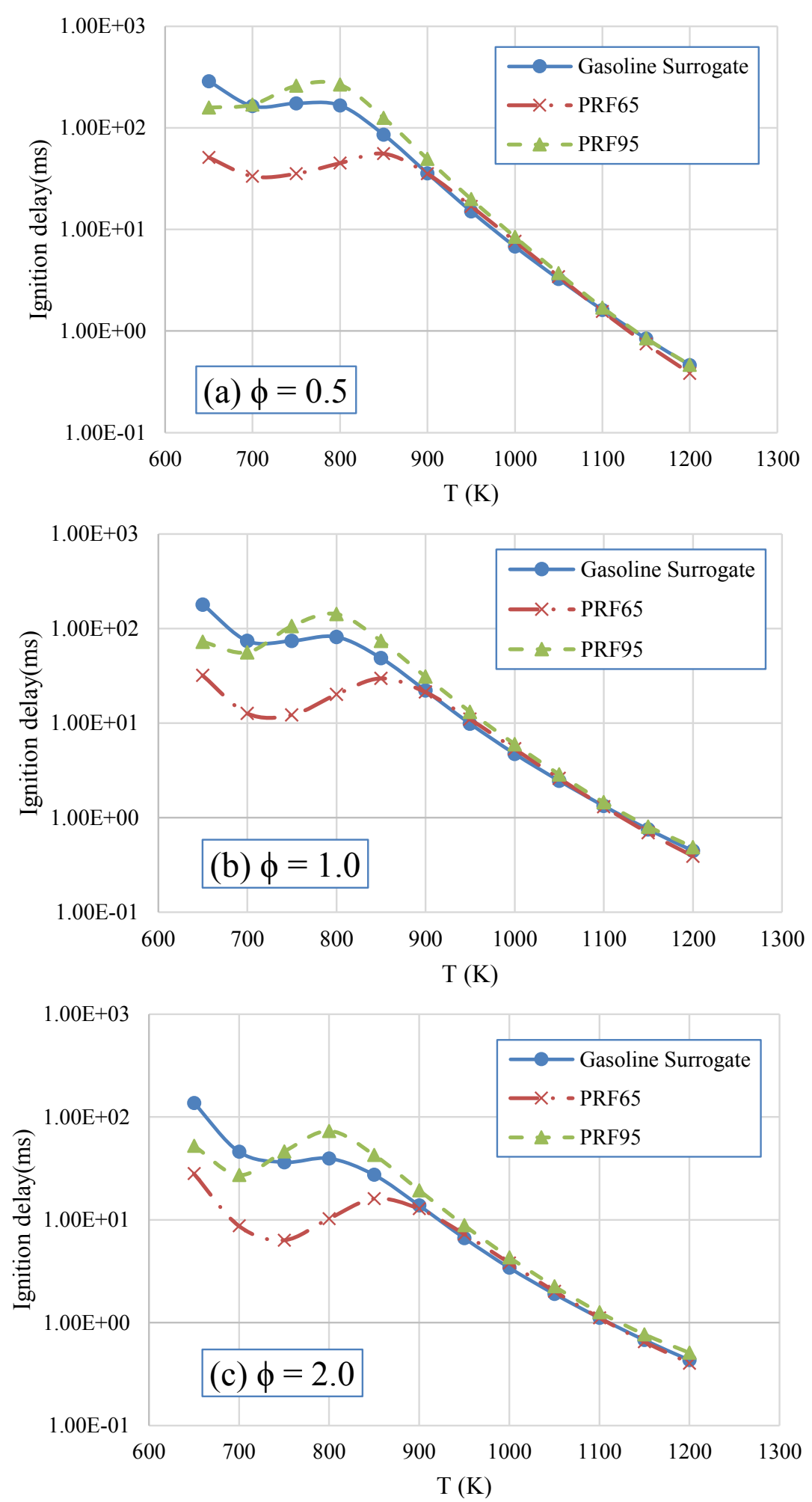

Figure 8. Calculated ignition delay time of the three surrogate fuels (PRF65, PRF95, and Gasoline surrogate) under different temperatures and an ambient pressure of $800 \mathrm{kPa}$ (8 bar): (a) equivalence ratio of 0.5 ; (b) equivalence ratio of 1.0 ; and (c) equivalence ratio of 2.0 


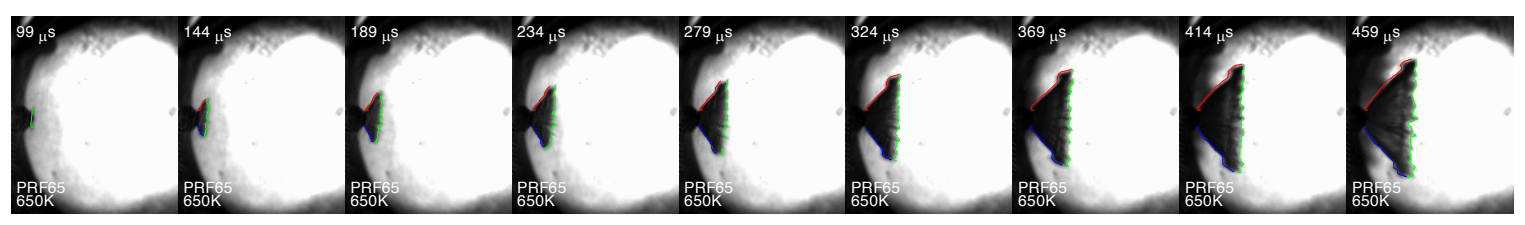

(a) PRF65 spray images under $650 \mathrm{~K}$ and $657 \mathrm{kPa}$ ambient condition

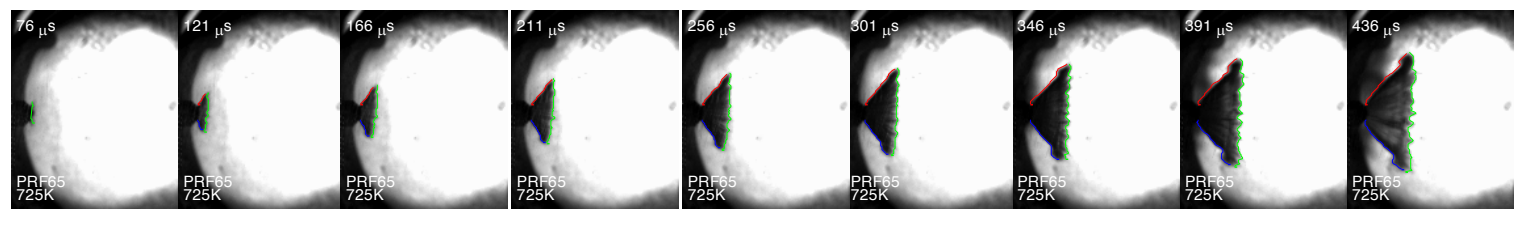

(b) PRF65 spray images under $725 \mathrm{~K}$ and $733 \mathrm{kPa}$ ambient condition

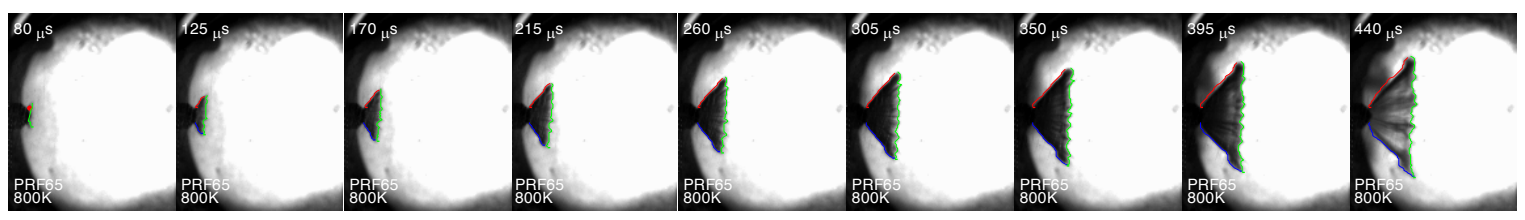

(c) PRF65 spray images under $800 \mathrm{~K}$ and $809 \mathrm{kPa}$ ambient condition

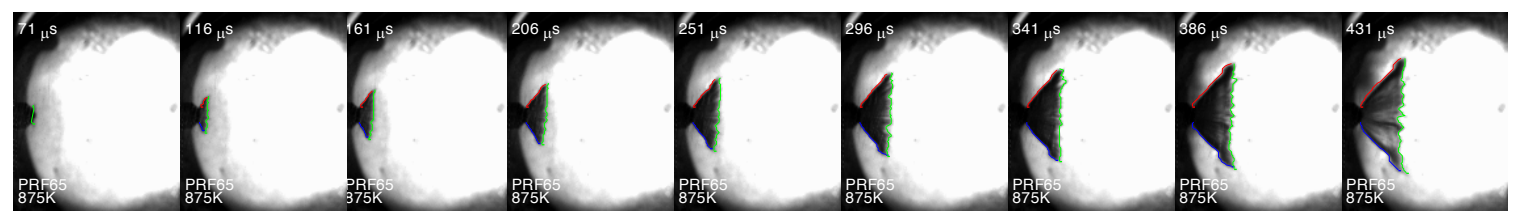

(d) PRF65 spray images under $875 \mathrm{~K}$ and $884 \mathrm{kPa}$ ambient condition

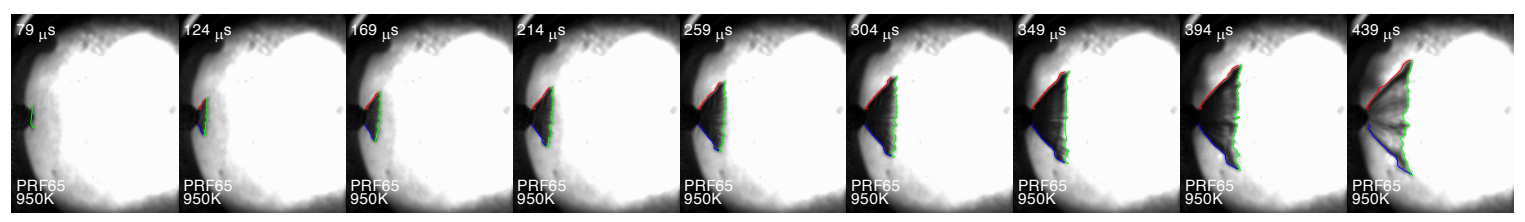

(e) PRF65 spray images under $950 \mathrm{~K}$ and $960 \mathrm{kPa}$ ambient condition

Figure 9. PRF65 spray images before ignition under different ambient temperature and pressure conditions while the ambient density is kept the same at $3.5 \mathrm{~kg} / \mathrm{m}^{3}$ 


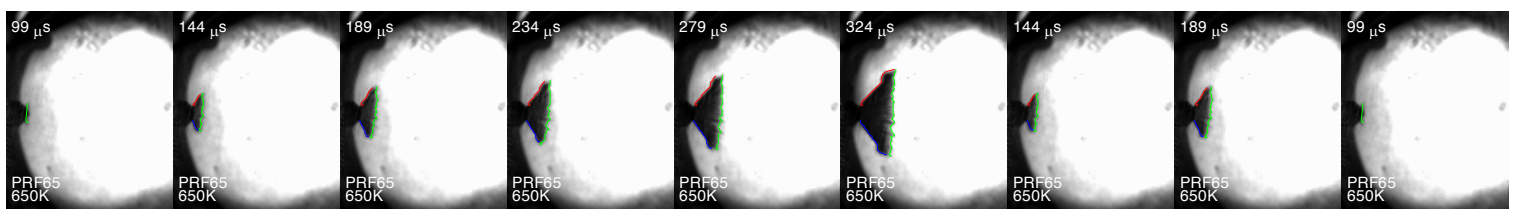

(a) PRF65

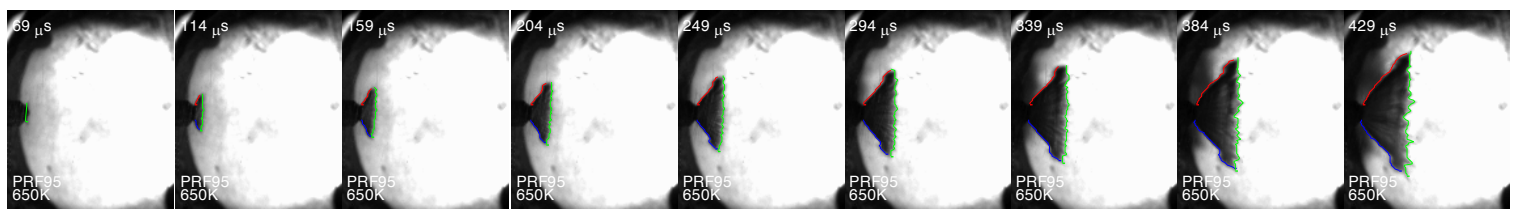

(b) PRF95

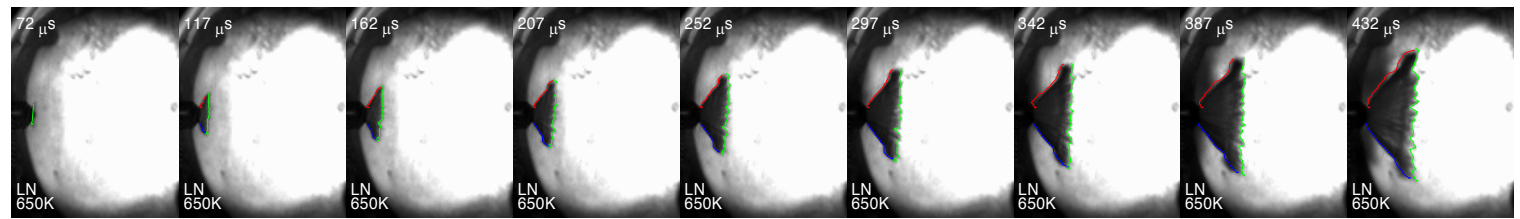

(c) $\mathrm{LN}$

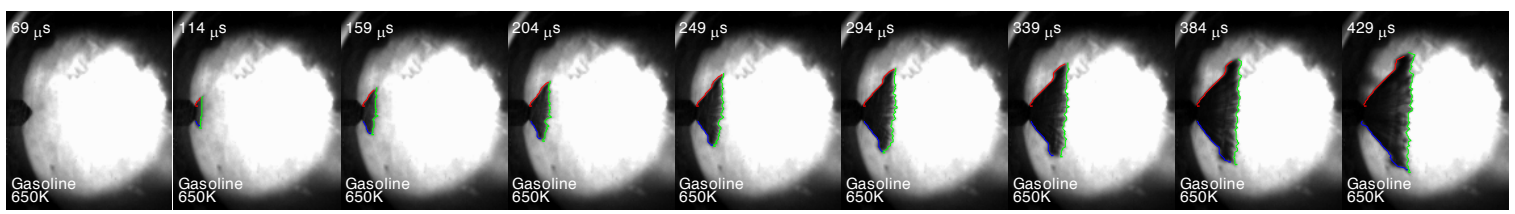

(d) Gasoline

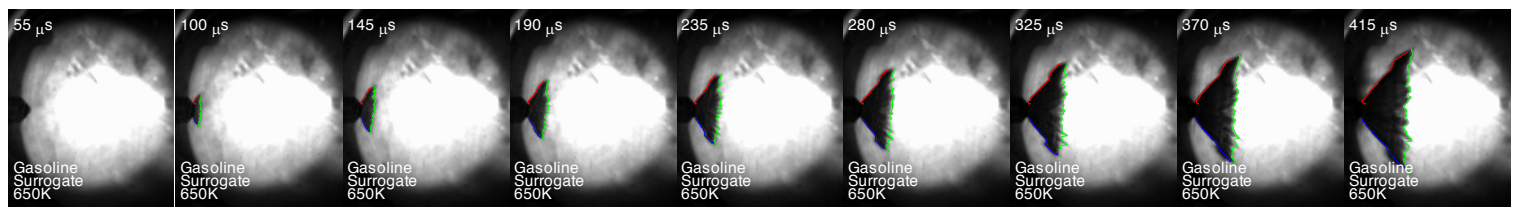

(e) Gasoline surrogate

Figure 10. Comparison of fuel spray before auto-ignition of five fuels at $650 \mathrm{~K}$ and $657 \mathrm{kPa}$ ambient conditions with a density of $3.5 \mathrm{~kg} / \mathrm{m}^{3}$ 


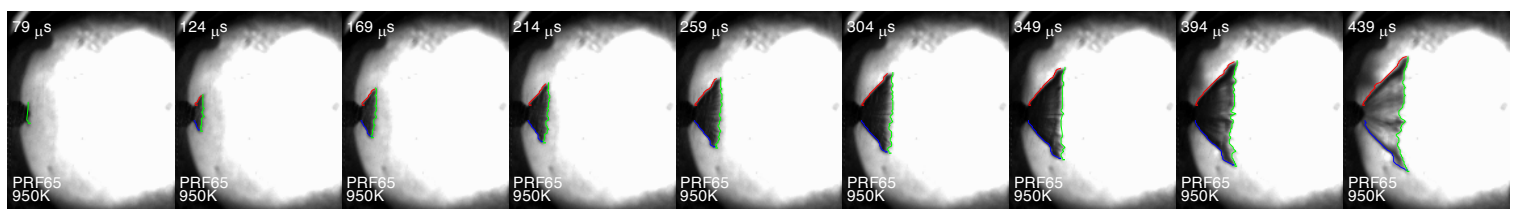

(a) PRF65

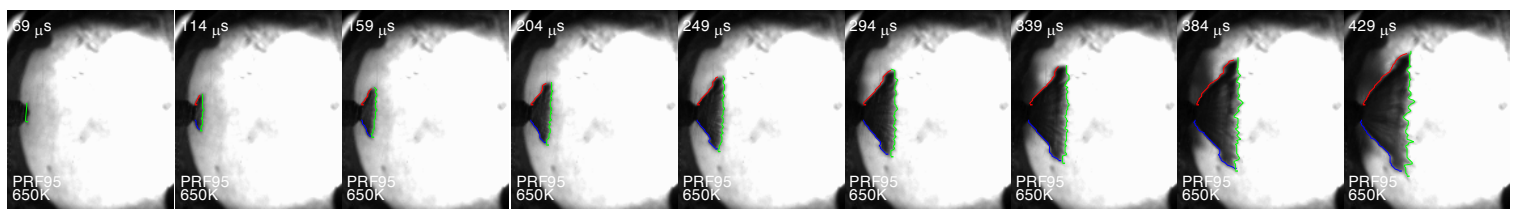

(b) PRF95

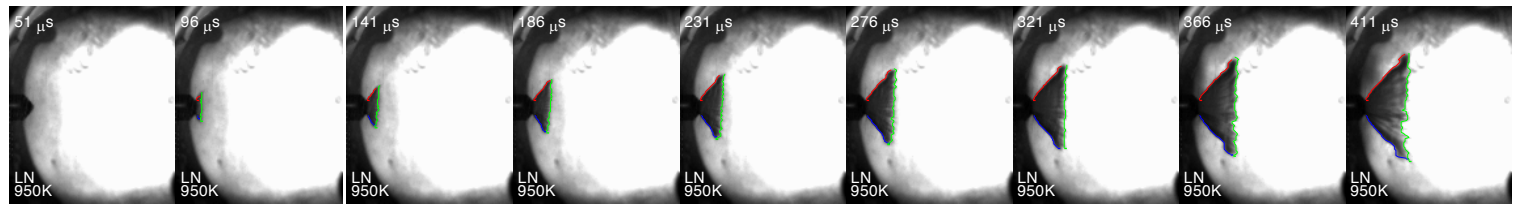

(c) LN

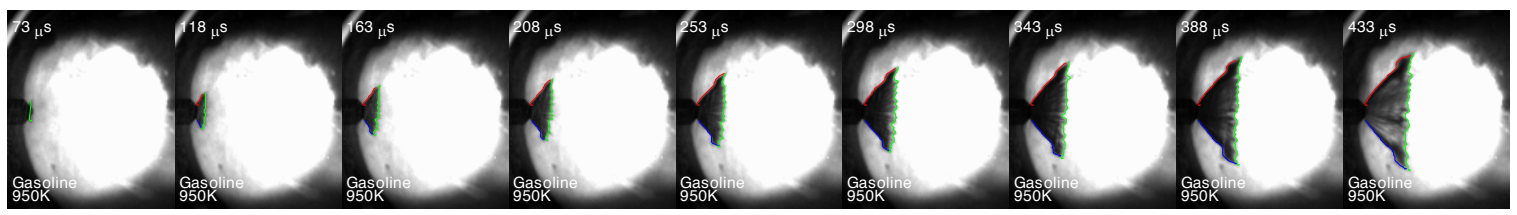

(d) Gasoline

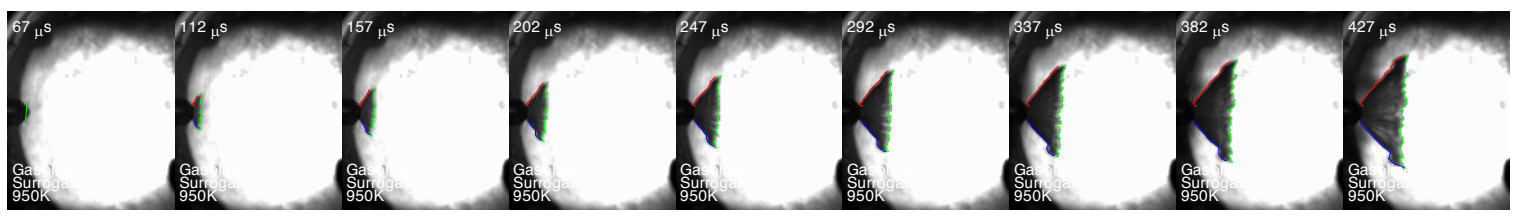

(e) Gasoline surrogate

Figure 11. Comparison of fuel spray before auto-ignition of five fuels at $950 \mathrm{~K}$ and $960 \mathrm{kPa}$ ambient conditions with a density of $3.5 \mathrm{~kg} / \mathrm{m}^{3}$ 


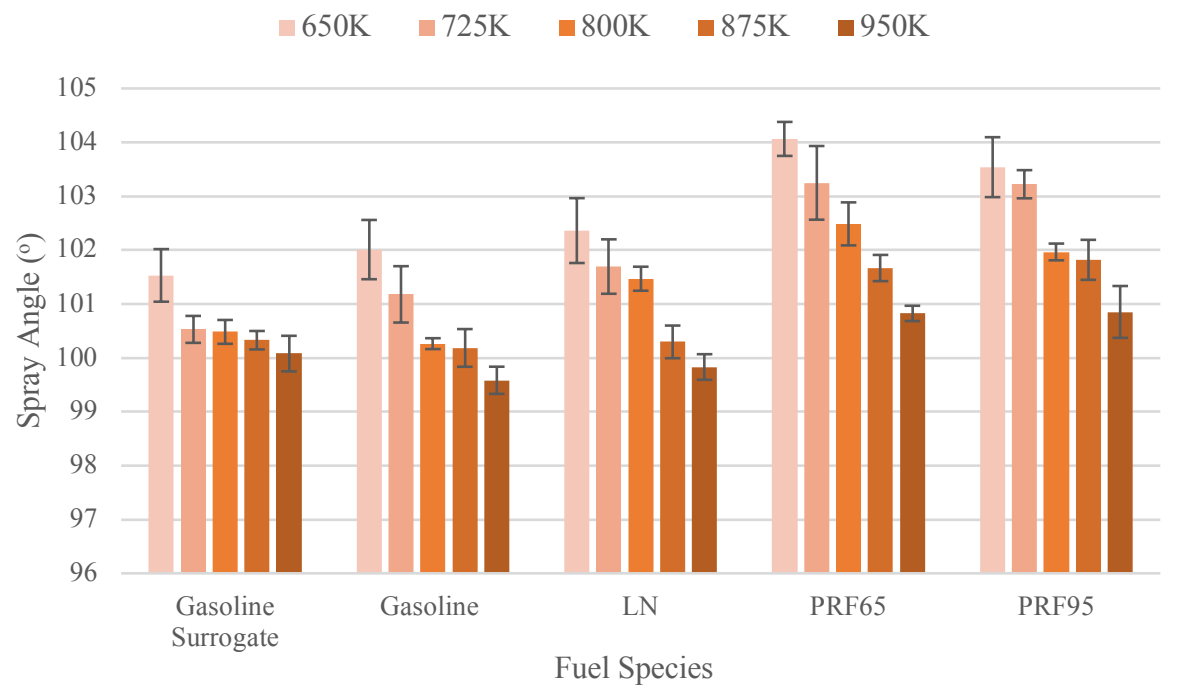

Figure 12. Time averaged spray angle for each fuel under different ambient temperatures

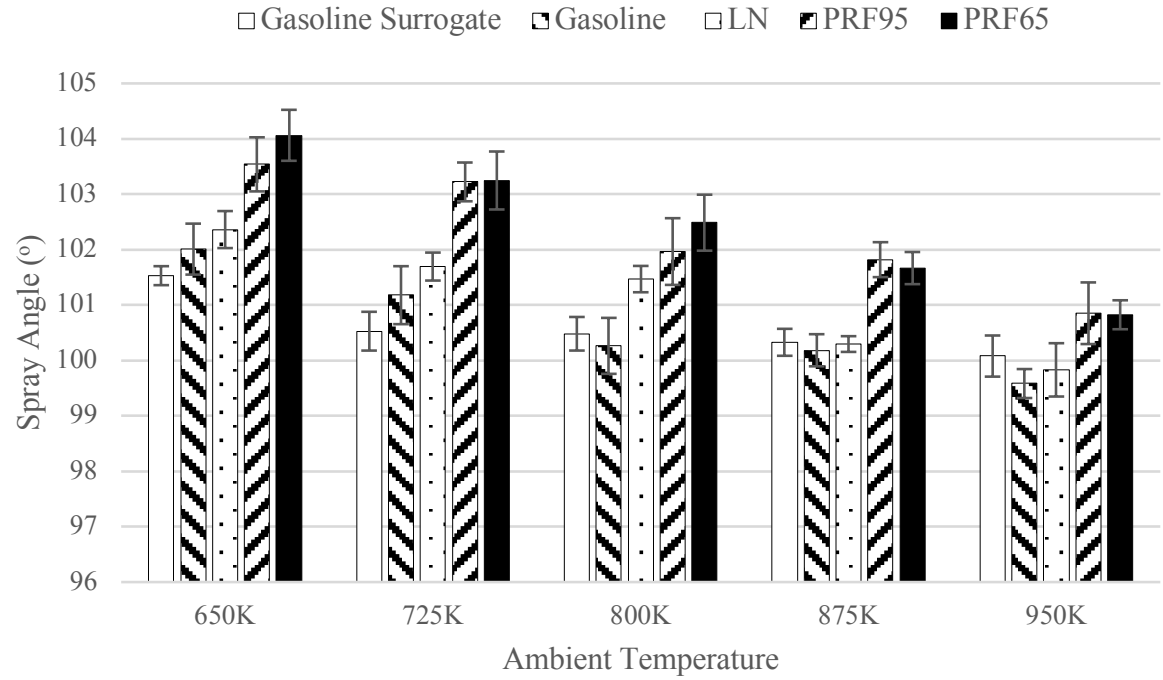

Figure 13. Comparison of time averaged spray angle among five fuels under different ambient temperatures 

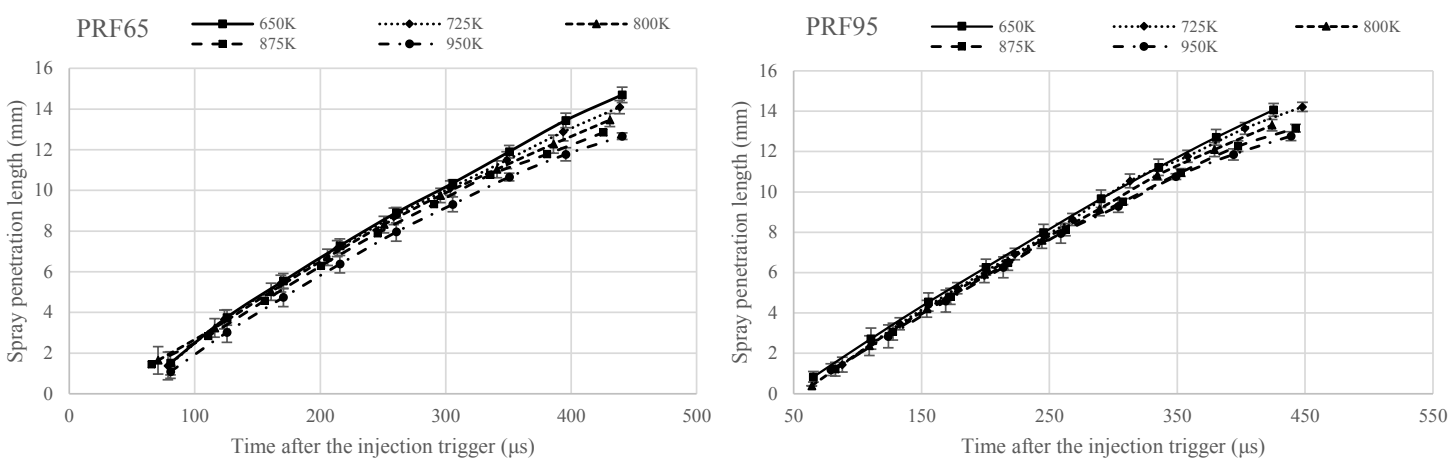

(a) PRF 65

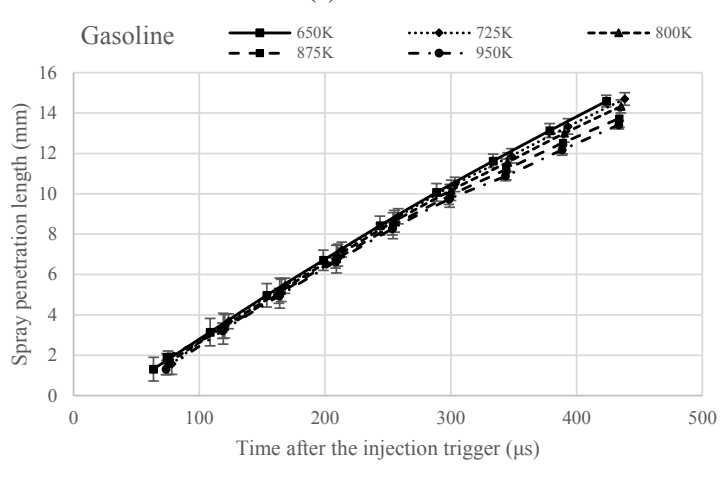

(b) PRF 85

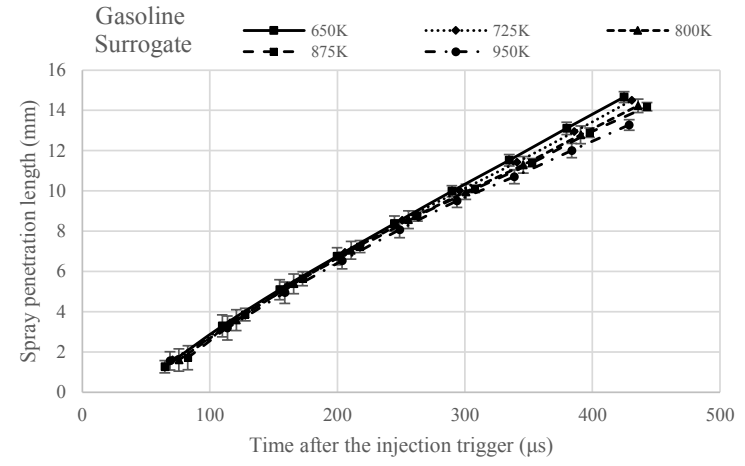

(c) Gasoline

(d) Gasoline Surrogate

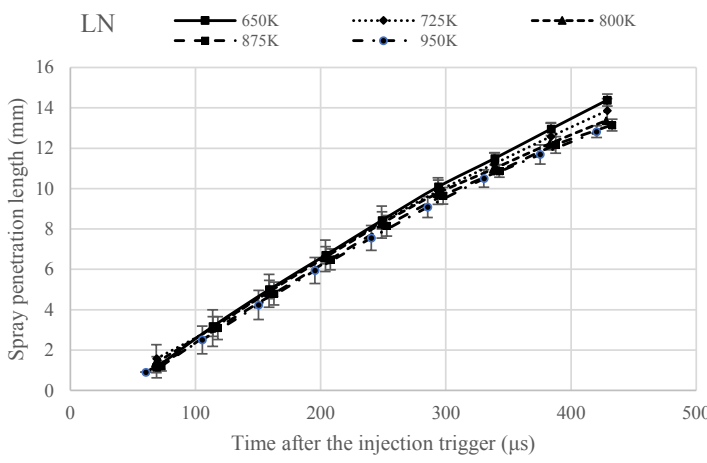

(e) $\mathrm{LN}$

Figure 14. Spray front penetration length of five fuels under different ambient temperatures 


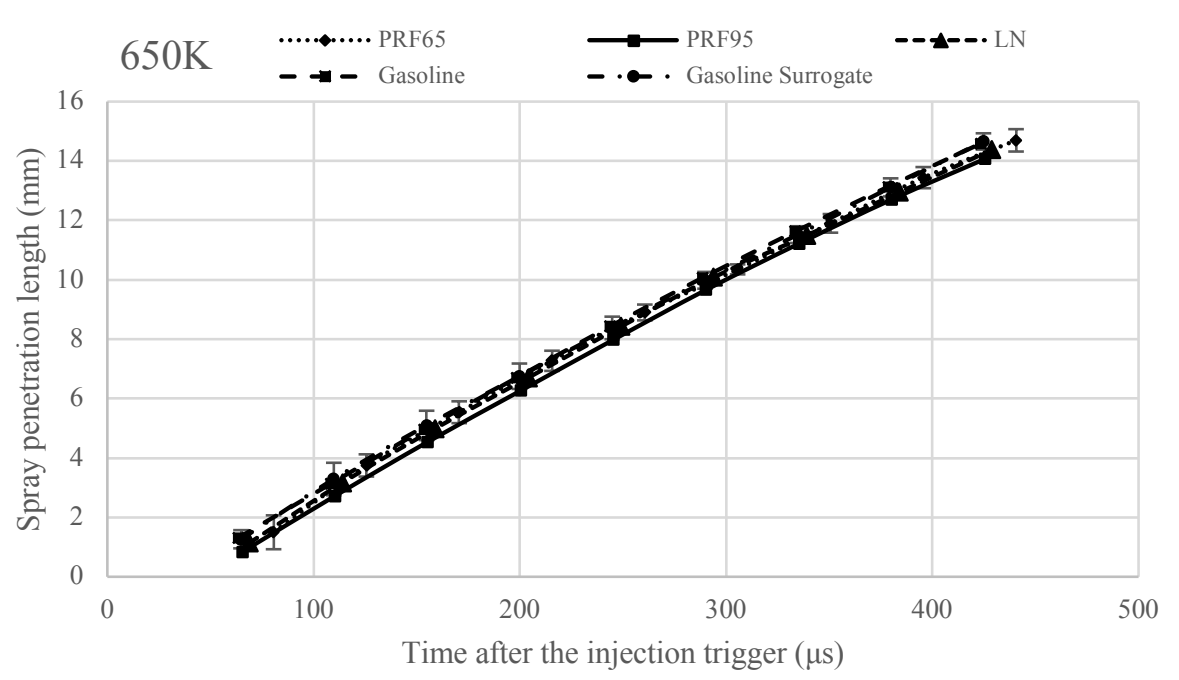

(a) $650 \mathrm{~K}(657 \mathrm{kPa})$

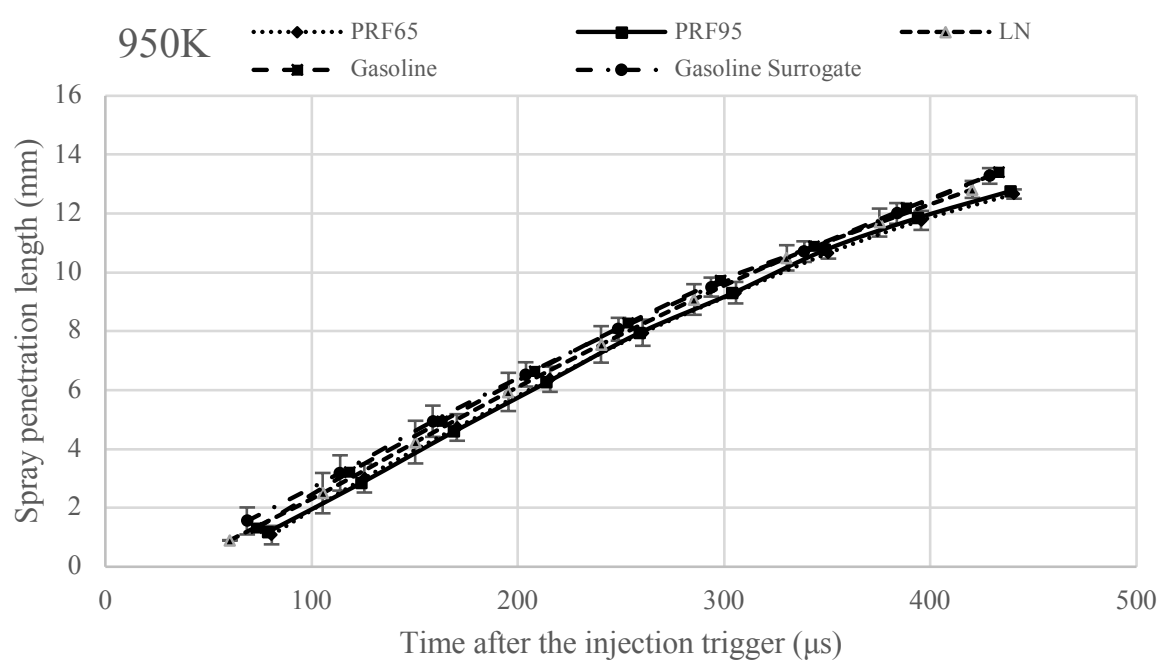

(b) $950 \mathrm{~K}(960 \mathrm{kPa})$

Figure 15. Comparison of spray front penetration length among five fuels at: (a) $650 \mathrm{~K}$, (b) $950 \mathrm{~K}$ 


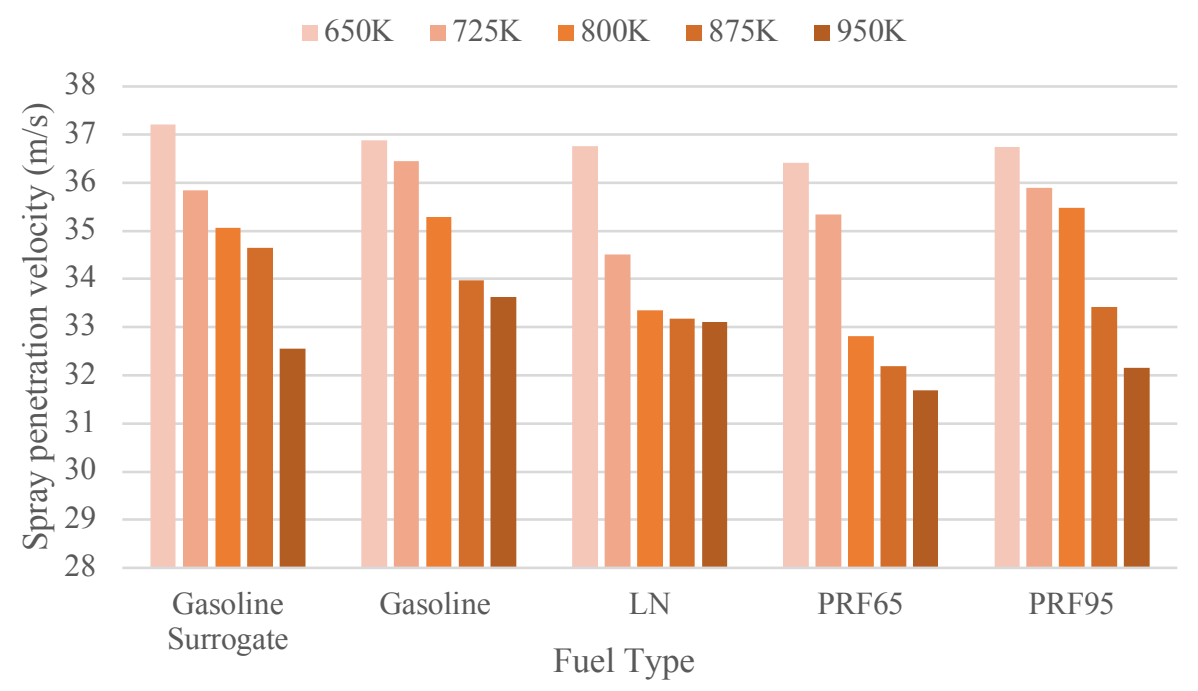

(a)

$\square$ Gasoline Surrogate Gasoline $\quad \square$ LN $\quad$ PRF95 घPRF65

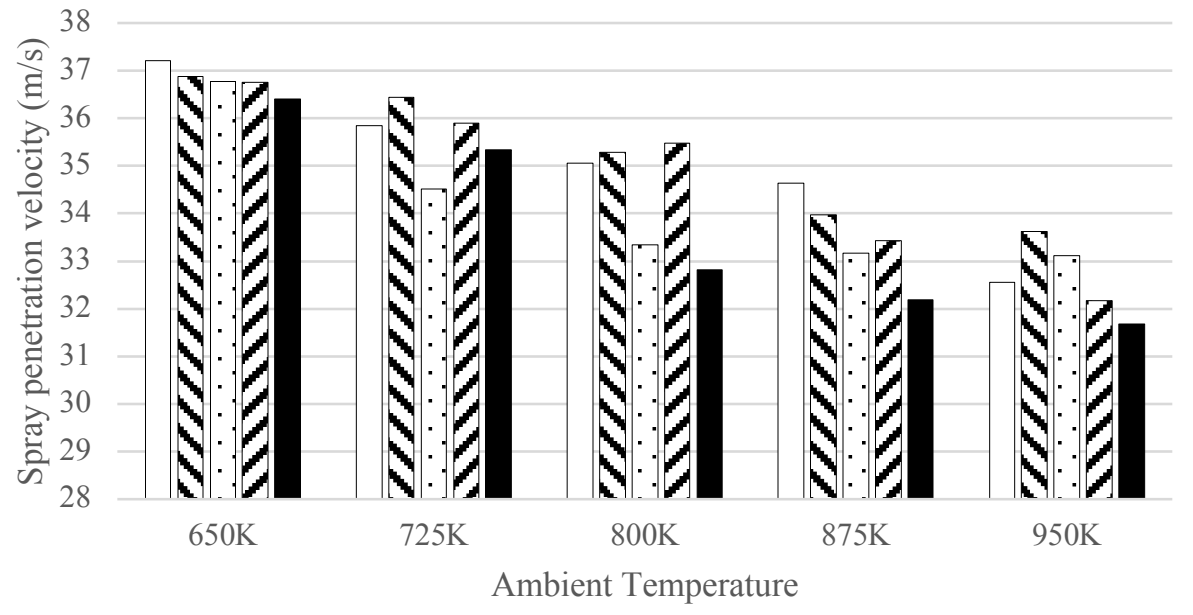

(b)

Figure 16. Comparison of spray front penetration velocity among five fuels (a) and under different temperatures (b) 